\title{
A quantitative assessment of intraspecific morphological variation in Gahagan bifaces from the southern Caddo area and central Texas
}

\author{
Robert Z. Selden, Jr. ${ }^{\text {a,b,c }}{ }^{*}$, John E. Dockall ${ }^{\mathrm{d}, \mathrm{e}}$, and Morgane Dubied ${ }^{\mathrm{f}}$ \\ ${ }^{a}$ Heritage Research Center, Stephen F. Austin State University, United States \\ ${ }^{b}$ Cultural Heritage Department, Jean Monnet University, France \\ ${ }^{c}$ ORCID ID 0000-0002-1789-8449 \\ ${ }^{d}$ Cox/McLain Environmental Consulting, Inc., United States \\ ${ }^{e}$ ORCID ID 0000-0002-0940-7144 \\ ${ }^{f}$ UMR 6282, Laboratoire Biogéosciences, Université de Bourgogne, France
}

\begin{abstract}
This investigation aggregates intact or reconstructed Gahagan bifaces from the southern Caddo area and central Texas to test the hypothesis that Gahagan biface morphology differs between the regions. The Gahagan bifaces $(\mathrm{n}=102)$ were scanned, then analysed using a novel landmarking protocol and the tools of geometric morphometrics. Results provide a preview of the significant differences in Gahagan biface morphology expressed between the southern Caddo area and central Texas regions. The size discrepancy represents an inversion of current theoretical constructs that posit a decrease in tool size thought to articulate with an increase in distance from the raw material source. It is posited that the contrasting morphologies represent two discrete communities of practise; one (emergent Caddo horticulturalists) where Gahagan bifaces were enlisted primarily for burial and ritualistic activities, and the other (central Texas hunter-gatherers) where Gahagan bifaces were utilised over a longer time span in more practical and utilitarian contexts.
\end{abstract}

Keywords: NAGPRA, 3D geometric morphometrics, computational archaeology, archaeological science, virtual archaeology, museum studies, repository studies, digital humanities, STEM

\footnotetext{
${ }^{*}$ Corresponding author, Robert Z. Selden, Jr. (zselden@sfasu.edu)
} 
The mathematical definition of a "form" has a quality of precision which was quite lacking in our earlier stage of mere description; it is expressed in few words, or in still briefer symbols, and these words or symbols are so pregnant with meaning that thought itself is economised (Thompson, 1917, 720-721).

This contribution follows a recent study of Gahagan biface morphology that enlisted the three largest samples in the southern Caddo area from the Gahagan Mound (16RR1), George C. Davis (41CE19), and Mounds Plantation (16CD12) sites (Figure 1) (Selden Jr. et al., 2018). The results of that study indicated a significant difference in shape between Gahagan bifaces found at the Mounds Plantation site compared with those found at the Gahagan Mound and George C. Davis sites (Selden Jr. et al., 2018, Figure 7). The test for morphological disparity indicated that the sample from Gahagan Mound occupied a significantly greater range of morphospace than the sample from Mounds Plantation, providing limited evidence for discussions of specialisation and diversity. Morphological integration was also significant, meaning those traits used to characterise Gahagan biface shape (blade and base) were found to vary in a coordinated manner. These results confirmed the supposition advanced by Shafer (1973) that the assemblage of Gahagan bifaces from the George C. Davis site compares favourably with those reported from the Gahagan Mound site (Moore, 1912; Webb and Dodd Jr., 1939).

The shape difference identified in the previous study occurs across the same geography as a difference in Smithport Plain and Hickory Engraved (Caddo) bottle shapes (Selden Jr., 2018a,b, 2019a,b). The difference in Caddo bottle morphology has been attributed to two Formative/Early Caddo communities of practise - one north, and the other south - where the same decorative motifs were applied to two distinct bottle shapes. The shape boundary found to occur in Smithport Plain and Hickory Engraved bottles (Selden Jr., 2019b, Figure 1) 


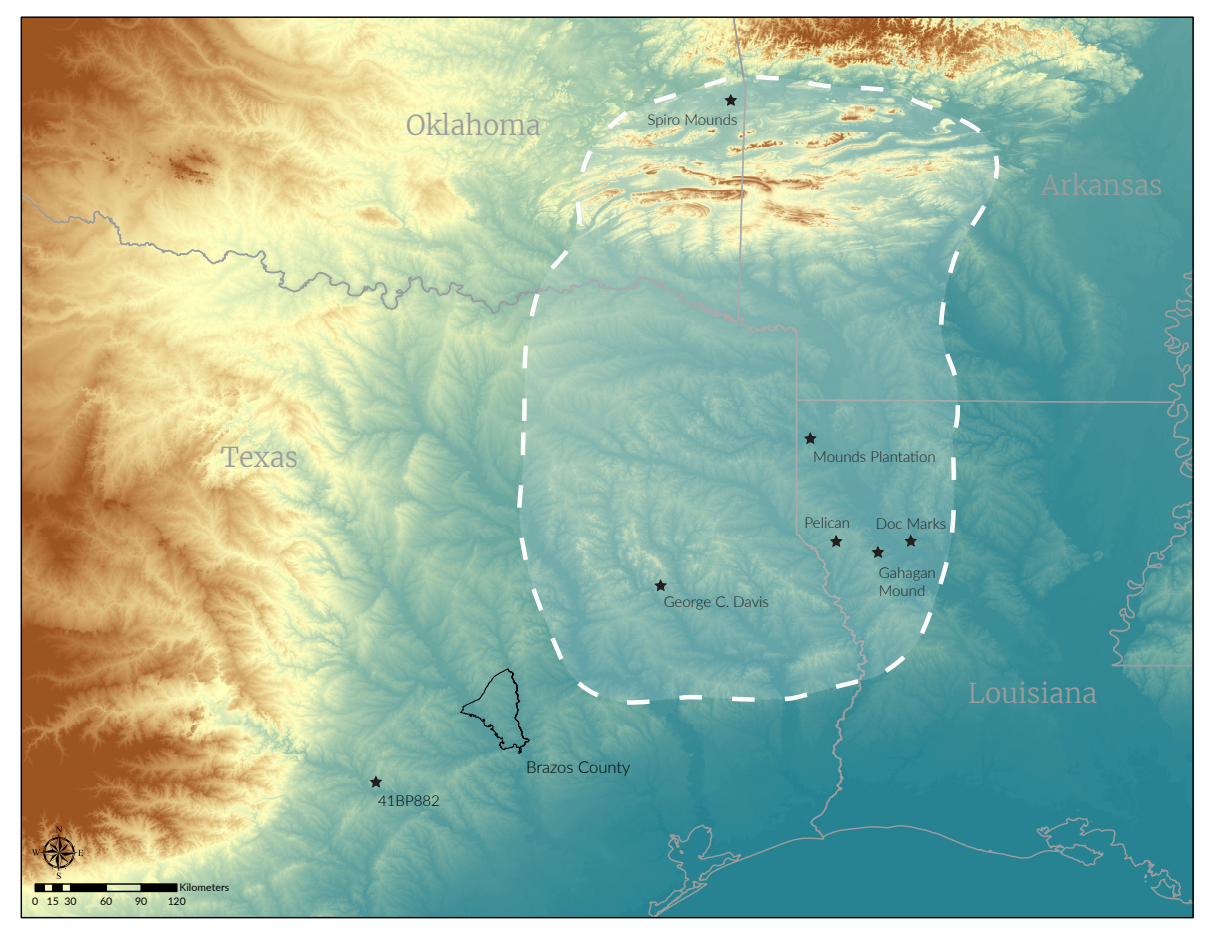

Figure 1: Site locations for collections used in the analysis. Southern Caddo area in white, and Brazos County (outlined in black) located to the southwest. The Doerge collection is from Brazos County, Texas, and the provenance of the BVMNH collection is unknown, but assumed to be central Texas.

also manifests in Gahagan bifaces where the difference in shape was expressed spatially between the Gahagan Mound and Mounds Plantation sites (Selden Jr. et al., 2018).

The Gahagan type was suggested by Clarence H. Webb at the Caddo Conference in 1970 (Shafer, 1973), and was intended as a replacement for those specimens that Newell and Krieger (1949) considered Copena knives based upon what they saw as similarities in form, but not technology, between bifaces found at the George C. Davis site in east Texas and those reported by Webb and DeJarnette (1942) in Alabama. Gahagan bifaces were named for the finely-crafted bifaces discovered by Moore (1912) at the Gahagan Mound site. Shafer (1973) 40 later argued that Gahagan and Copena bifaces differ in both morphology and 
technology, but did not include a discussion of technological differences in his analysis of Gahagan bifaces from the George C. Davis site. Shafer $(2006,22)$ would later advance a formal description for the type; however, a discussion of those technological attributes needed to discriminate Gahagan from Copena 45 bifaces was not included.

Additional specimens were added from known Caddo sites (Doc Marks and Pelican), and the whole of the sample from the southern Caddo area is contrasted with those recovered from central Texas sites (Bastrop State Park and the Doerge Collection), including one unprovenienced collection from the Brazos Valley Museum of Natural History (BVMNH) (Figures 1 and 2). The Doerge Collection is a large private collection donated to the BVMNH, and includes the largest collection of Gahagan bifaces found outside of the southern Caddo area (Shafer, 2006, Table 5) (Figure 2, a9-s9). No site-specific details were provided to the museum related to context, association, or cultural affiliation;

55 however, the museum was informed that the whole of the collection was from Brazos County, Texas. Another small collection of Gahagan bifaces are curated at BVMNH (Figure 2, a8-h8), are unprovenienced, and assumed to come from the central Texas region. The single specimen from Bastrop State Park (Figure 2, a6) was found on the surface at the Rylander site (41BP882) by Emmy Lyn 6o Francell, and is curated at the Texas Parks and Wildlife Department. There are no chronometric dates associated with any of the central Texas archaeological contexts used in this study; however, Gahagan bifaces have been recovered from dated contexts at the J. B. White (41MM341) (Gadus et al., 2006) and Baker (41SS192) sites (Hixson and Whitley, 2020), which are included in the chronological models produced for this study.

Preliminary visual observations point to significant morphological differences between Gahagan bifaces recovered from Caddo and central Texas sites. Gahagan bifaces are a morphological type that are regularly interpreted to be diagnostic of Formative and/or Early Caddo occupations (Shafer, 2006, 1973).

7o Should the morphology of Gahagan bifaces from central Texas be found to differ from those recovered in the southern Caddo area, additional theoretical expla- 

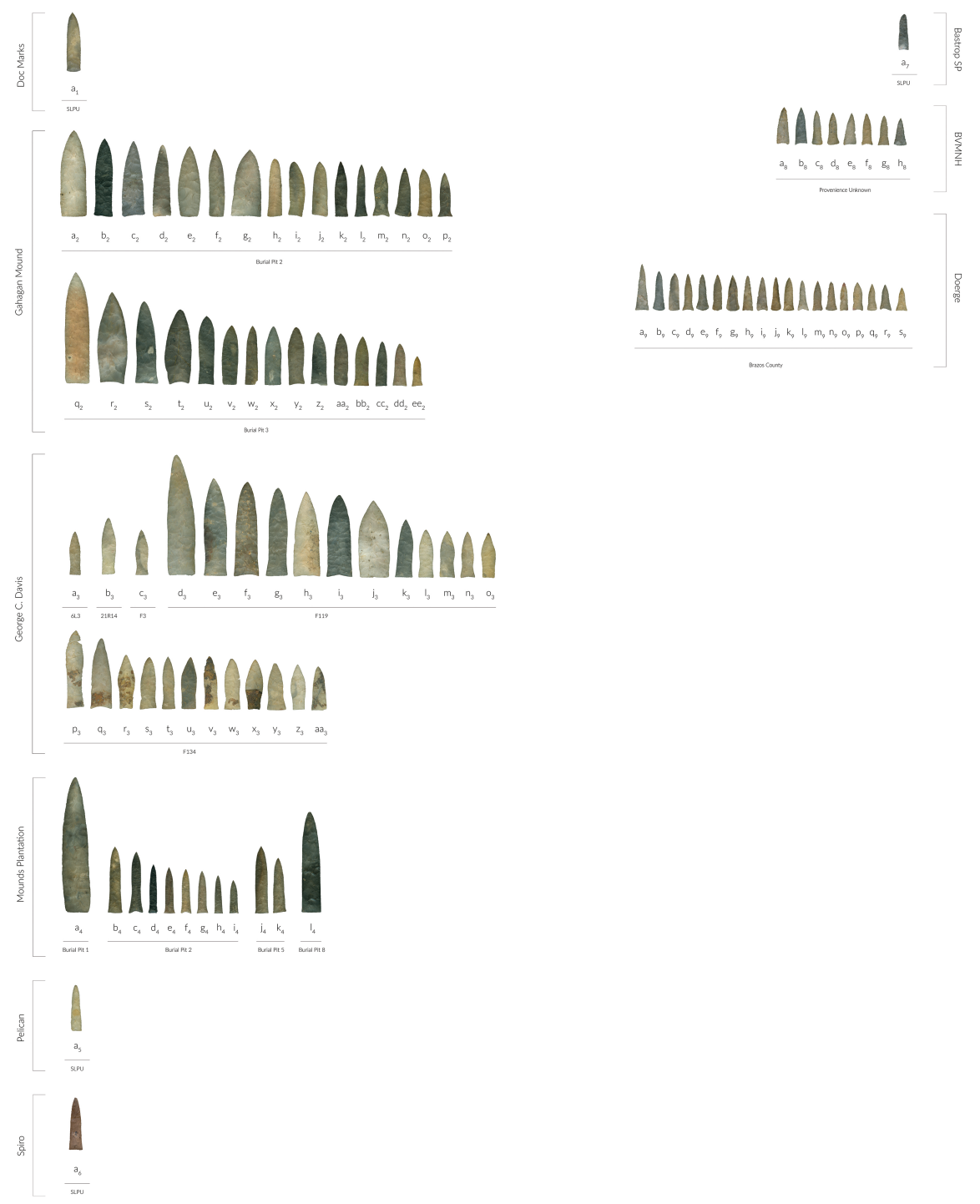

Figure 2: Gahagan bifaces from the southern Caddo area (left) and central Texas (right) regions organised by context and length; a1, no site-level provenience; a2, 569; b2, 543; c2, 551 ; 2,$541 ;$ e2, 546; f2, 544; g2, 545; h2, 489; i2, 532; j2, 548; k2, 550; 12, 533; m2, 549; n2, 547; o2, 490; p2, 542; q2, 593; r2, 666; s2, 605; t2, 622; u2, 606; v2, 609; w2, 623; x2, 608; y2, 607; z2, 662; aa2, 611; bb2, 610; cc2, 612; dd2, 613; ee2, 614; a3, ET221-993; b3, ET221-1260A; c3, ET221-1016; d3, 463-1; e3, 424-39; f3, 424-53; g3, 424-50; h3, 424-41; i3, 424-221; j3, 424-218; k3, 463-16; 13, 424-230; m3, 463-23; n3, 424-169; o3, 424-33; p3, 4078-8; q3, 4078-9; r3, 4078-11; s3, 4078-72; t3, 4078-45; u3, 4078-12; v3, 4078-13; w3, 4078-72; x3, 4078-14; y3, 4078-32; z3, 4078-22; aa3, 4078-14; a4, 3Ba90; b4, 3Bb6; c4, 3Bb1; d4, ThnBlk; e4, 3Bb7; f4, 3Bb3; g4, 3Bb4; h4, 3Bb8; i4, 3Bb5; j4, Case2LG; k4, Case2SM; 14, LGGray; a5, no site-level provenience; a6, no site-level provenience; a7, no site-level provenience; a8 - h8, no provenience; a9 - s9, Brazos County, Texas. Bifaces w2, z2, and aa3 were not used in the analysis due to basal fractures, but are included here for visual comparative purposes. Additional information for each specimen, including the option to download individual 2D images, can be found at https://scholarworks.sfasu.edu/ita-gahaganbiface/. 
nations may be warranted.

Context

The flexuous blade shapes associated with Gahagan bifaces from Burial 1

75 at the Gahagan Mound site led to the initial interpretation that they were knives (Moore, 1912, Figures 18-21). A subsequent investigation at the Gahagan Mound site (Webb and Dodd Jr., 1939) classified the bifaces into two different biface types (both currently designated as Gahagan bifaces); one made of dull gray chert with a square base and a symmetrical or curved knife form, and the other made of semi-translucent flint with a curved base and more strongly curved sides. In Burial Pit 2 at Gahagan Mound (Webb and Dodd Jr., 1939, Plate 21), one Gahagan biface (Figure 2, a2) (Webb and Dodd Jr., 1939, Plate 27, No. 1,3 ) was found near the left shoulder of an adult male (Skeleton 3), but most artefacts were recovered near the northwest margin of the burial pit, including 85 the remaining Gahagan bifaces associated with that context. In Burial Pit 3 at Gahagan Mound (Webb and Dodd Jr., 1939, Plate 23, 1), one Gahagan biface was found near the left femur of Skeleton 1 (Figure 2, r2) (Webb and Dodd Jr., 1939, Plate 27, No. 1, 2). Similar to Burial Pit 2, most of the artefacts from Burial Pit 3 were found along the northwest margin, including the remainder of 9o Gahagan bifaces from that context (Webb and Dodd Jr., 1939).

At the George C. Davis site, two Gahagan bifaces were found outside of mound or feature contexts (Figure 2, a3 and b3), and their feature assignments (6L3 and 21R14) articulate with the excavation grid used by Newell and Krieger (1949). Feature 3 is associated with a 27 -foot diameter ring of 35 postholes lo95 cated east of Mound A (Newell and Krieger, 1949, Figure 4), where one Gahagan biface (Figure 2, c3) was found in the outlining postholes (Newell and Krieger, 1949).

Feature 134 is associated with a Stage I burial feature at the George C. Davis site that predates the construction of Mound C, and contained eight individuals 100 (Story, 1997, 1972). One large (48 cm), well-thinned biface that Story $(1997,22)$ listed as a "Gahagan?" biface was found near the right leg of Skeleton 5. Shafer 
(1973, Figure 19x) included this specimen - and one additional large specimen from Feature 119 (Shafer, 1973, Figure 19w) - in his Group 2 bifaces due to a lack of fine pressure-flaked margins definitive of Group 1 (Gahagan) bifaces. Nine Gahagan bifaces from Feature 134 were recovered from Concentration 2; seven (Figure 2, p3-r3, u3, v3, x3, and aa3) were found "about and under gray pigment," and two others were found outside of the pigmented area (Figure 2, s3, w3) (Story, 1997, 21-23 and Figure 12). Organic residue can still be found on a selection of these Gahagan bifaces (Selden Jr. et al., 2018, Figure 2), which Shafer $(1973,228)$ notes, "may be the remains of leather or bark sheaths or cane wrapping." Three additional Gahagan bifaces (Figure 2, t3, y3, and z3) were found in Concentration 3 (Story, 1997, 21-22 and Figure 12).

Feature 119 (Story, 1997, Figure 13-18) articulates with a Stage II burial feature at the George C. Davis site that can be traced from the surface of the second mound stage, and included offerings associated with two discrete layers (Story, 1997, 1972, 1969). The first layer offerings include Gahagan bifaces from Concentration 1 (Figure 2, o3), Concentration 2 (Figure 2, e3, g3, h3, and n3), and Concentration 3 (Figure 2, f3, i3, j3, and 13). Second layer offerings include Gahagan bifaces associated with Concentration 1 (Figure 2, d3), Concentration 3 (Figure 2, m3), and Skeleton 1 (Figure 2, k3).

Burial Pit 2 at Mounds Plantation is the only context that contained a single individual, and Webb and McKinney (1975, 97) noted (of the Gahagan bifaces) that "fine edge retouch leaves the edges with almost no serration or irregularity, altogether the finest flint knapping that we have seen from a Caddoan site" (Figure 2, b4-i4). The bifaces from Burial Pit 2 at Mounds Plantation were found in a bundle, but those from Burial Pit 5 articulate with the males of Groups 1 and 2 (Figure 2, j4 and k4, respectively), and were found in a context parallel to the left forearm, pointed toward the hand (Webb and McKinney, 1975, Figure 5). The biface from Burial Pit 8 at Mounds Plantation (Figure $2,14)$ was found in the same position on the left forearm; however, the largest biface (Burial Pit 1, Skeleton 1; see Figure 2, a4) was found across the chest of that individual (Webb and McKinney, 1975). 
McKinney posited that Gahagan bifaces may have been carried in a sheath attached to the left forearm (Webb and McKinney, 1975). Similarly, Shafer 135 (1973) noted that - at the George C. Davis site - edge modification was confined to traces of polish and smoothing along the widest blade segments and near the tip on burial specimens, was more pronounced on specimens from non-mound contexts, and possibly represented sheath wear. The polish that Shafer (1973) discussed supports McKinney's hypothesis (Webb and McKinney, 1975), where the tip and lateral edges of the bifaces may have become polished while being worn in a sheath on the left forearm with the tip pointed toward the wrist.

\section{Chronometric dating}

Emerson and Girard (2004, Table 1) reported three AMS radiocarbon dates from Burial Pit 2 at the Gahagan Mound site. The first (UGA12296), from Deposit 3 in Burial Pit 2, was fragmented wood-possibly cypress-from a copper-covered wooden object that Webb and Dodd Jr. (1939, 99, Plate 29, No. 2, Object 5) describe as a pendant in the shape of an animal claw (Emerson and Girard, 2004). The second (ISGS A0465), found adjacent to the head of Skeleton 3 (adult female) in Burial Pit 2, was unidentifiable fragmented wood that Webb and Dodd Jr. (1939, 96, Plate 21 and 28, Nos. 2-3) describe as square ear ornaments of copper-coated cypress wood (Emerson and Girard, 2004). The third (ISGS A0466), from Deposit 2 in Burial Pit 2, was not described by Webb and Dodd Jr. (1939, 96), but Emerson and Girard (2004, 62) describe it as a leather-covered copper object.

155 Story and Valastro Jr. (1977, Table 1) reported two radiocarbon dates (Tx913 and Tx-1206) from contexts associated with the special mortuary in Mound $\mathrm{C}$ at the George C. Davis site where Gahagan bifaces were found (Story and Valastro Jr., 1977, Table 5). The date from Feature 119 (Tx-913) is associated with the green fill placed atop Caddo remains in the Stage II burial in Mound C (Story and Valastro Jr., 1977). The date from Feature 134 (Tx-1206) provided an age that Story and Valastro Jr. (1977) believed to be inconsistent with the stratigraphic position of the sample, thus it is excluded from the chronological 
model. Neither of the legacy dates from the George C. Davis site account for isotopic fractionation.

Webb and McKinney $(1975,72)$ reported three dates from two logs found in Burial Pit 5 at the Mounds Plantation site. Two of those (Tx-55 and M1446), both from Log 1, were described by Webb and McKinney $(1975,72)$ as coming "from the upper set of timbers, about $50 \mathrm{~cm}$ above the pit floor." The third (Tx-56), from Log 6, was described by Webb and McKinney $(1975,72)$ as coming from "Log $6 \ldots$ nearer the center of the pit and just above the pit floor." None of these three legacy dates account for isotopic fractionation. Webb and McKinney (1975) omit the $\log 6(\mathrm{Tx}-56)$ date from further discussions of the site, thus it is omitted from the chronological model. None of the legacy dates from the Mounds Plantation site account for isotopic fractionation.

There are no strong associations at the J. B. White site (41MM341) between biface type and analysis unit, mostly because the sample is so small. Of those bifaces and biface fragments recovered, shape could only be determined for 11 specimens. Three have the classic Gahagan shape, and four express morphological attributes characteristic of Friday bifaces. Both occur in Analytical Units (AU) 1 and 2, and a date of CE 895 was proposed as the start of AU2, but that possibly extends to CE 780. Neither biface type was encountered in AU3 (Gadus et al., 2006, 139). Dates within the report were not modeled, leading to difficulties in determining the temporal boundaries of AU1 and AU2 (Gadus et al., 2006, 136).

The Gahagan biface recovered from the Baker site (41SS192) was part of what Hixson and Whitley (2020) identified as the pre-Toyah component. This component is limited to small $(0.5 \mathrm{~m})$ charcoal-stained sub-circular areas in Block 2 of the excavation that included burned rocks and bone fragments (Hixson and Whitley, 2020). The Gahagan biface was found in a shovel test along the terrace edge in association with similar arrow points found in Block 2 (Hixson and Whitley, 2020). Thus, the authors argue that while the date does not articulate directly with the same context as the biface, it should be considered part of the same component. Cultural materials from this area of the site were 
nearly as dense as that found in Block 2 (Hixson and Whitley, 2020). Given the loose association of Gahagan bifaces with the dated contexts at the Baker site, two chronological models are presented. One includes the Baker site dates, and the other does not.

Chronometric dates from those contexts listed above were included in the chronological model for Caddo contexts where Gahagan bifaces have been found; one with the Baker site dates (Figure 3, top), and the other without (Figure 3, bottom). The oxcAAR library (https://github.com/ISAAKiel/oxcAAR) was used to build the chronological model in $\mathrm{R}$, which was executed using OxCal 4.3.2 (Ramsey, 1995, 2017) and the IntCal13 calibration curve (Reimer et al., 2013). The chronological model demonstrates the modeled probability distributions at the beginning and end of the southern Caddo area and central Texas phases (Selden Jr., 2020). Additional details associated with the chronological model can be found in the supplemental materials (Selden Jr., 2020). Results illustrate that the starting and ending probability distributions for the southern Caddo area exhibit temporal overlap with the start of the central Texas tradition; although, the Caddo were potentially using this biface type earlier than their central Texas counterparts, who employed the type for a longer span in both models (Selden Jr., 2020).

\section{Manufacture}

Shafer (1973) discerned that all raw materials used in the manufacture of 215 Gahagan bifaces found at the George C. Davis site were from non-local sources, which was a noteworthy revision to the initial interpretation by Newell and Krieger (1949), in which the raw materials were considered to be of local origin. Further support for Shafer's assertion is added in his discussion of the fragility of specimens coupled with the absence of failures in the extensive excavations at George C. Davis (Shafer, 1973). This observation was expanded with findings from other locations (Banks and Winters, 1975), where investigators believed Gahagan bifaces to have been manufactured with Woodford, Battiest, and Ogallala cherts, as well as cherts from the Kiamichi Mountains. Shafer 


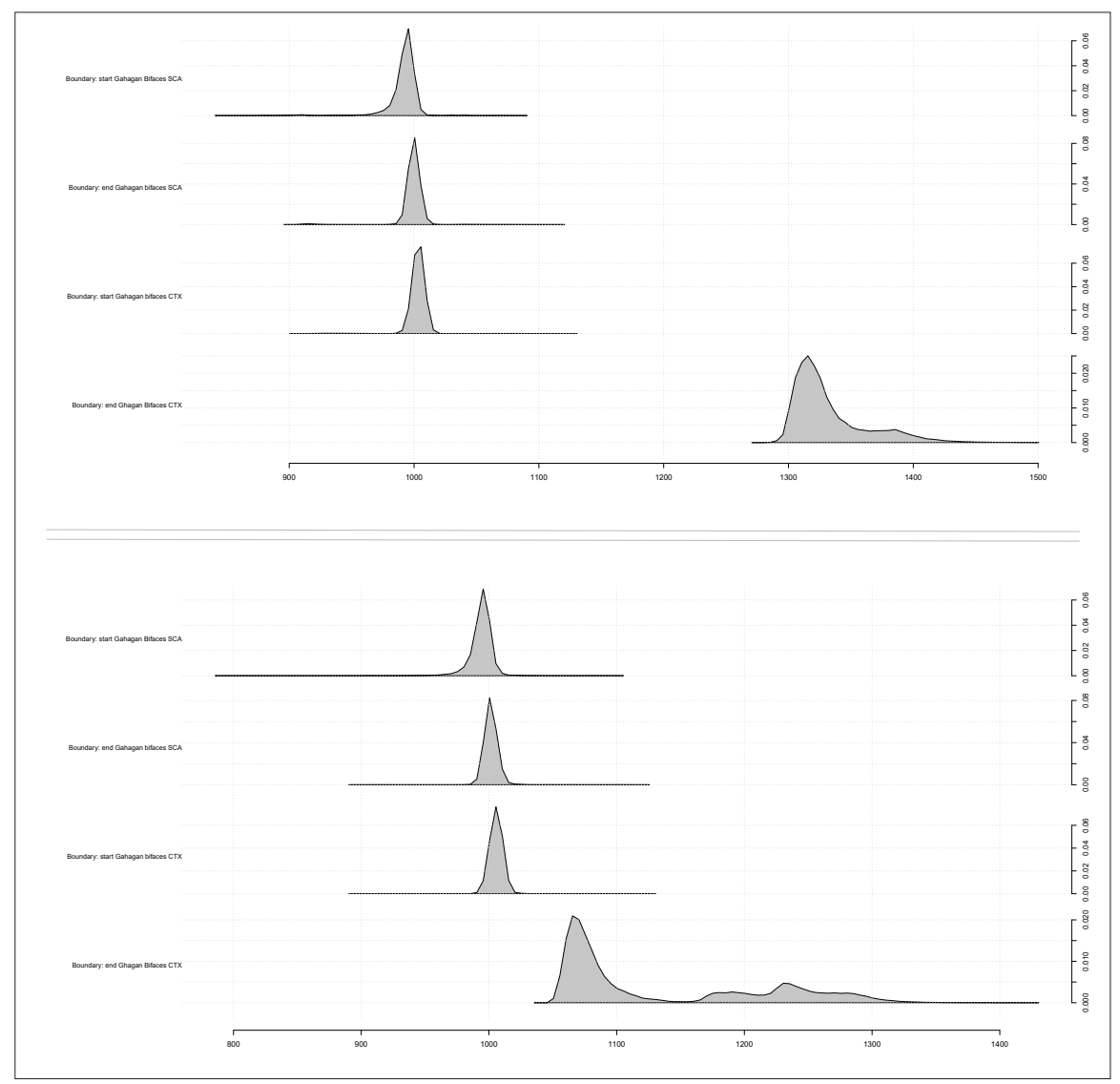

Figure 3: Start/end probability distributions for modeled dates (CE) articulating with southern Caddo area and central Texas contexts yielding Gahagan bifaces. The model at top includes those dates from the Baker site, and the model at bottom does not (Selden Jr., 2020). Plots for each modeled phase are included in the supplemental materials, along with the code used to generate this figure. Both can be found at https://github.com/akselblaise/gahaganmorph2/blob/master/analysis/gahagan14c.md.

(1973) also noted the size and shape of Gahagan bifaces from the Davis site to 225 be more uniform in Feature 134 compared with those from Feature 119, and that differences in the size of Gahagan bifaces from non-burial contexts were more striking than differences in shape. Shafer (1973) provides evidence for the presence of use-wear and fracture patterns on specimens from non-mound con- 
texts at George C. Davis, suggesting that Gahagan bifaces from Caddo contexts may have functioned similarly to those used by hunter-gatherer groups. In the analysis of debitage from George C. Davis, Shafer (1973) argued that limited biface manufacture occurred at the site, but none of that debitage is directly attributable to Gahagan biface manufacture.

In addition to those Gahagan bifaces found at mound sites in the southern Caddo area, there is abundant evidence that similar bifaces were manufactured by contemporary hunter-gatherer groups in central and east-central Texas. Sites with evidence of manufacture and use can be found across a series of locations that fringe the eastern edge of the Balcones Escarpment (Quigg et al., 2014, Figure 5-3). Each site is geographically situated on or within a zone of high-quality nodule and ledge cherts that may have served as source material. Gahagan bifaces found at these sites are represented by complete and incomplete specimens in varying stages of manufacture, use, maintenance, and discard. This indicates that bifaces were a commonly employed component of the overall lithic technology of central and east central Texas aboriginal groups, and likely used to perform a variety of common tasks.

A recent study tested the hypothesis that the manufacture of flat, thin bifaces - like Gahagan bifaces — would have yielded flatter bifacial thinning flakes that express low flake curvature (Quigg et al., 2014). The goal of that undertaking was to identify whether the flakes were distinctive enough on their own to warrant the assignment of potential Gahagan biface production locales, providing indirect evidence for association with the Prairie Caddo model (Shafer, 2006) in the absence of diagnostic artefacts (Quigg et al., 2014). The results of that study demonstrated that bifacial thinning flake curvature was not sufficient as a marker of Gahagan biface production locales (Quigg et al., 2014).

255 In contrast to the Gahagan Mound, George C. Davis, and Mounds Plantation samples, there are currently no recorded instances of Gahagan bifaces from contexts in central Texas that might be interpreted as mortuary, religious, or ceremonial. Whether or not these bifaces served to denote individual status among hunter-gatherer groups is unknown, but they may have functioned 

Caddo groups to the east.

Production evidence is present at contemporary sites distributed on the eastern edge of the Balcones Escarpment. Sites like Urbankte (41CV26) and Penny Winkle (41BL22 and 41BL23), Iron Bridge (41BL47), Hoxie Bridge (41WM130), McDonald (41HI105), Loeve-Fox (41WM230), Grimes Houey (41CV17), J. B. White (41MM341) and locations on Fort Hood, have all yielded specimens representing manufacture, use, and discard (Bond, 1978; Gadus et al., 2006; Miller and Jelks, 1952; Prewitt, 1982; Shafer, 2006; Shafer et al., 1964). Shafer posited that these bifaces were manufactured through a mix of hard and soft hammer percussion, as well as indirect percussion using a punch (Shafer, 2006, 1973). Flake scar patterns on many Gahagan bifaces support the inference that indirect percussion was used as a shaping and thinning technique. Isolated finds across Bell, Williamson, Milam, McLennan, and other counties in central Texas suggest that Gahagan bifaces were manufactured and used in these areas (Shafer,

\section{Analytical framework}

This basic research endeavour (Bush, 1945) consists of an exploratory analysis (Figure 4), and enlists the tools of geometric morphometrics to test whether Gahagan biface shape, size, and form differs between two archaeological regions. that incorporate questions of complex 3D geometry. Examples from the literature cover a broad scope of artefact categories including projectile points (Shott, 2011; Shott and Trail, 2010), bifaces (Archer and Braun, 2010; Archer et al., 2015, 2016; Selden Jr. et al., 2018), percussive tools (Caruana et al., 2014), flake 285 cars (Sholts et al., 2012), flake tools (Archer et al., 2017), handaxes (Lycett, 2009; Lycett et al., 2010, 2015; Lycett and von Cramon-Taubadel, 2013; Wang et al., 2012), and Caddo ceramics (Selden Jr. et al., 2014; Selden Jr., 2017, 2018b,a, 2019a,b).

It is not surprising that geometric morphometrics (sensu Corti (1993)) has 


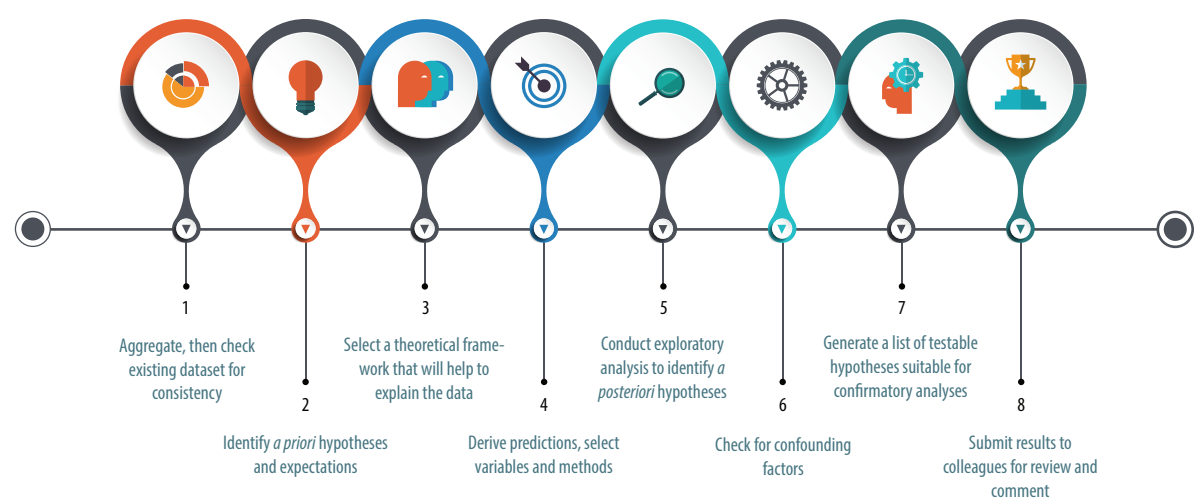

Figure 4: Workflow for the exploratory analysis used in this study. beveling, which occurs with some regularity along the lateral edges of Gahagan bifaces. 


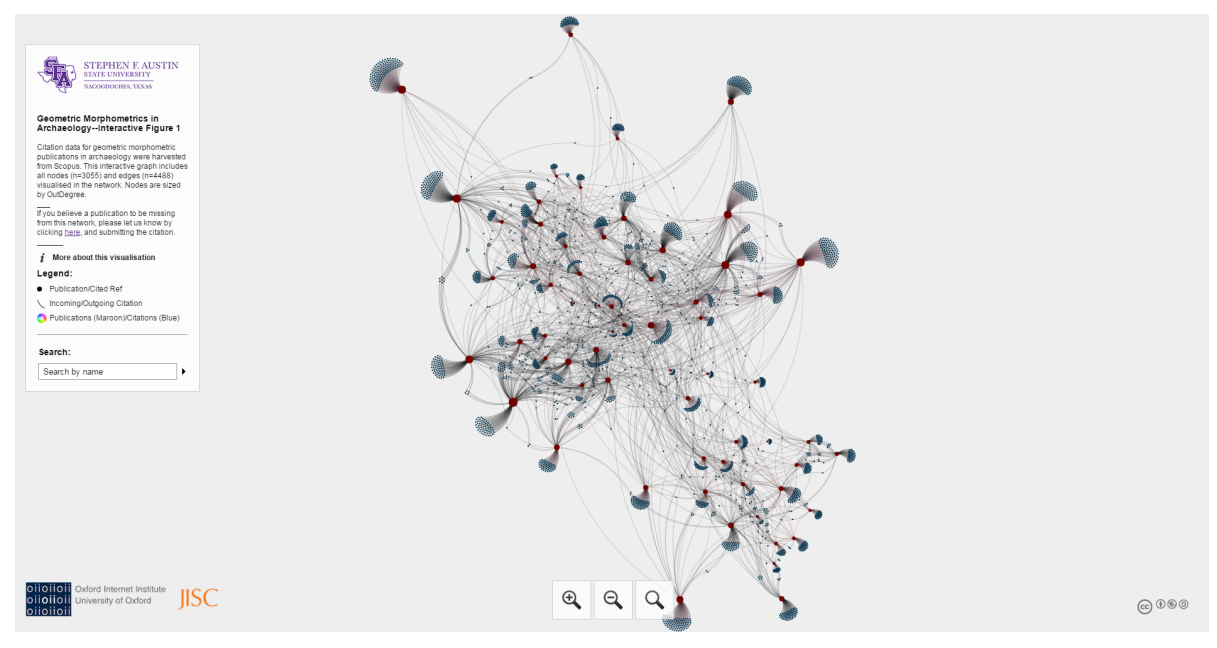

Figure 5: Interactive citation network for geometric morphometric studies in archaeology.

\section{Methods}

Each of the Gahagan bifaces was scanned with a Creaform GoSCAN 20 at a $0.3 \mathrm{~mm}$ resolution in VXelements. Scanner calibration was optimised prior to each scan with positioning targets required for increased accuracy and shutter speed reconfigured in each instance. A clipping plane was established to reduce the amount of superfluous data collected. Following data collection, the resolution of each mesh was increased to $0.1 \mathrm{~mm}$, and the point cloud was transferred to VXmodel where the mesh was rendered following application of the clean mesh function, used to remove isolated patches, self-intersections, spikes, small holes, singular vertices, creased edges, narrow triangles, outcropping triangles, narrow bridges, and non-manifold triangles prior to decimation and export as ASCII stl and ASCII ply files. The stl functions as a 3D print-ready backup of the scan data, and the ply file was subsequently processed using the Rvcg library in R 3.6.1 (Schlager, 2017; R Core Development Team,, 2020; Selden Jr., 2020).

There is a residue adhering to seven Gahagan bifaces from the George C.

Davis site at variable thickness (Selden Jr. et al., 2018, Figure 2). Shafer (1973, 228) posits that this residue potentially represents the remains of a sheath. 
While an interesting aside, the residue does pose a problem for an analysis of 3D geometry. The initial research design (3D) was thus revisited, leading to a reconfiguration of the previous analysis as a $2 \mathrm{D}$ geometric morphometric study

330 (Selden Jr. et al., 2018), enlisting a landmark configuration similar to that used by Buchanan and Collard (2010, Figure 2), Buchanan et al. (2011, Figure 2), and Ragan and Buchanan (2018, Figure 1). The residue does not occur on all of the George C. Davis specimens, and none of the Gahagan bifaces from the Mounds Plantation or Gahagan Mound sites include a similar residue on their surfaces, making it possible to compare a greater range of surface morphology between those samples.

The same basic constellation of landmarks was employed for this undertaking; however, unlike the previous iteration where landmarks were projected onto a 2D spline, landmarks in this iteration were plotted directly on the 3D spline, providing a means of capitalising on shape variation introduced through the practise of beveling. This configuration of landmarks will be revised for subsequent analyses, where additional semilandmarks will be added to capture morphological attributes associated with latitudinal and longitudinal cross-sections. The evolution of this research programme is focused not only upon aggregating 345 additional specimens, but capitalising on the various morphological nuances and complexities included in those designs. Two specimens in the George C. Davis sample (4078-8 and 4078-72), both from Feature 134, are missing small sections of their lateral edges (Figure $2 \mathrm{p} 3$, w3). For the purpose of the GM analysis, these areas were modeled, and the surface of the mesh was extended to include the area of the missing piece in both instances.

\section{Alignment and Landmarks}

The auto3dgm library (Boyer et al., 2015) was used in in R 3.6.1 (R Core Development Team,, 2020) to align the meshes using principal alignments calculated by minimising Procrustes distance between pseudolandmarks. Subjective 355 parameters used in the alignment included 250 initial points, and 1000 final points. The algorithm exported the aligned scans and a 3D image associated 
with the alignment and minimum spanning tree (MST) (Figure 6). The output from auto3dgm included the aligned meshes, an image of the resized and aligned meshes, and the MST. The image of the aligned bifaces produced by auto3dgm 360 (Figure 6a) was used as the basis for orienting the scans in 3D space throughout the landmarking process. The addition of auto3dgm into this workflow aids in reducing investigator bias - although algorithmic bias is still introduced - through providing a method of selecting which face of each Gahagan biface faces toward the investigator during the landmarking process. The MST (Figure 6b) has utility in generating hypotheses that can be tested in subsequent analyses. The alignment using auto3dgm was initially run in $\mathrm{R}$ (Figure 6), but the final alignment was run in SlicerMorph (https://github.com/SlicerMorph/SlicerMorph), where mirroring could be turned off.
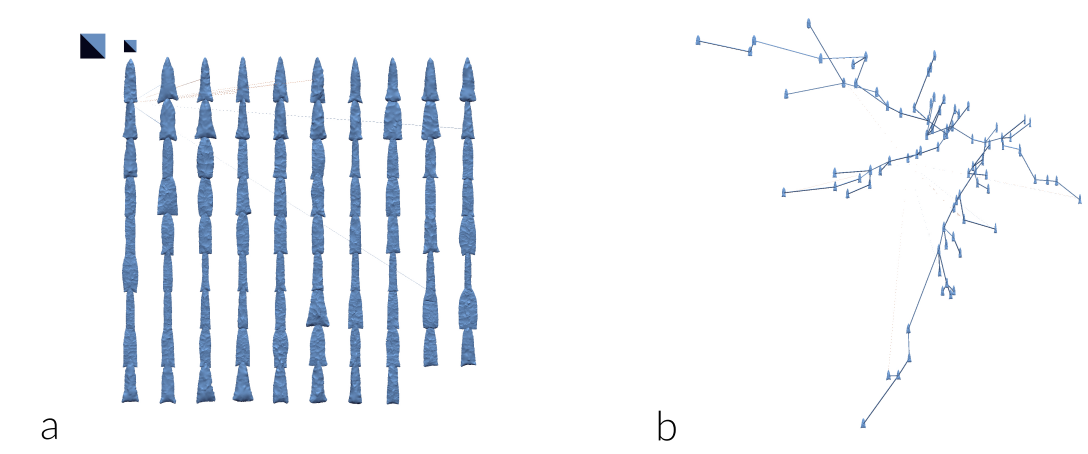

Figure 6: Size-standardised aligned meshes (a) and MST (b) generated by auto3dgm. The orientation of each biface provided in the auto3dgm output was used to orient the 3D meshes in advance of applying landmarks, and the MST can be used for hypothesis generation.

The digit3DLand library (https://github.com/morphOptics/digit3DLand) was used in R 3.6.1 (R Core Development Team,, 2020) to develop the landmark configuration employed in this study (Table 1). The shift to a 3D analysis was made due to the amount of beveling that occurs across the sample of Gahagan bifaces. The same basic configuration of landmarks and semilandmarks used in the previous study (Selden Jr. et al., 2018, Figure 3) was repurposed in this iteration; however, these landmarks and semilandmarks were placed directly on 
the mesh, providing a means of capitalising on the curvature that occurs along the sinuous lateral edges.

Table 1: Landmarks used in the analysis. The position of each biface in 3D space was determined using the auto3dgm alignment prior to applying the landmarks using digit3DLand.

\begin{tabular}{lcl}
\hline Landmark & Location & Definition \\
\hline Point01 & Tip & Horizontal tangent \\
Point02 & Blade/Base & Point of highest curvature on right side \\
Point03 & Blade/Base & Point of highest curvature on left side \\
Point04 & CentreBase & Equidistant between Points 2 and 3 \\
\hline
\end{tabular}

The final landmarking protocol developed for this study (Selden Jr., 2020) enlisted Geomagic Design X (Build Version 2019.0.2 (Build Number: 78]) to generate a spline around the periphery of each biface, and to populate the landmarks and equidistant semilandmarks in a replicable manner using mathematicallydefined criteria. The 3D landmark configuration increases both the precision and rigour of the study by including the z-dimension to capture those morphological characteristics associated with axial twisting that are introduced through the practise of bifacial beveling. This landmarking protocol represents an intermediate iteration between the previous 2D analysis (Selden Jr. et al., 2018), and the forthcoming protocol that includes semilandmarks placed on a series of equidistant cross-sections. The cross-sections increase the coverage of semilandmarks across the mesh topology, providing for greater precision in the analysis of morphology for the whole object. The evolution of this landmarking protocol represents a concerted effort to better comprehend the vagaries of morphological similarities and differences among Gahagan bifaces. While true that some landmarking protocols can be - and often are - recycled as new specimens are added, this particular research programme endeavours to achieve ever-greater accuracy and precision in each analytical iteration.

Unlike the previous study, where the outline of each Gahagan biface was projected onto a $2 \mathrm{D}$ plane, this effort enlists a spline extracted from the surface geometry of the mesh using the extract contour curves command to detect and 
extract 3D contour curves from high-curvature areas of the mesh (Figure 7). The extracted feature curve is rendered as a spline, and follows the highest curvature contours around the periphery of the lateral and basal edges, following the highly variable morphology of the sinuous edge around the entirety of the biface (Figure 7). The remainder of the landmarking protocol is based upon this spline, which was then split at four locations.

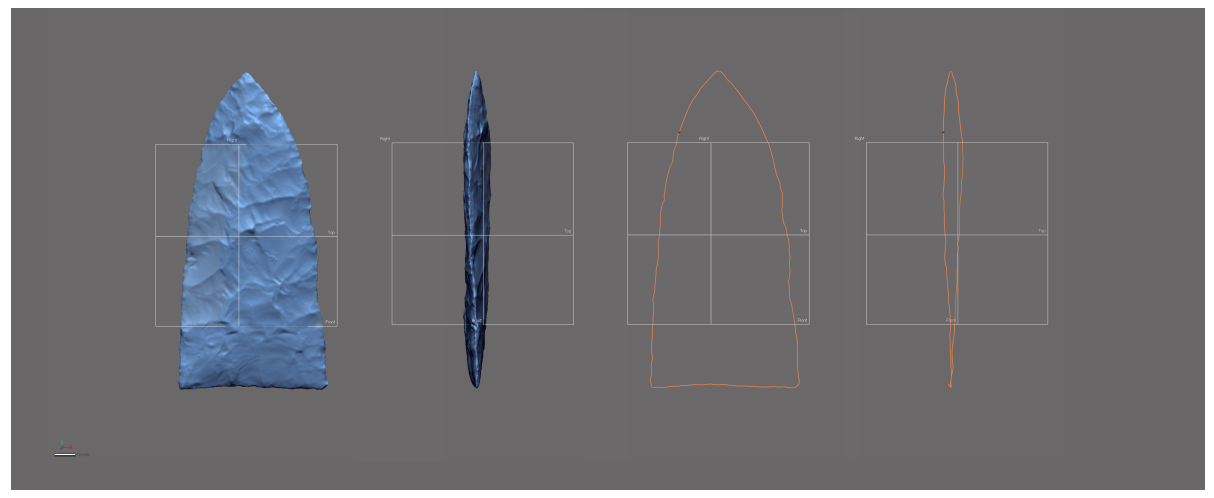

Figure 7: Spline extracted along the highest contours of the projectile. Additional information related to the landmarking protocol used in this study can be found in the supplementary material at https://github.com/akselblaise/gahaganmorph2/blob/master/analysis/landmarking-protocol.md (Selden Jr., 2020).

The characteristic points and tangents developed for this landmarking protocol were inspired by the work of Birkhoff (1933). The first landmark (LM1) is placed at the horizontal tangent on the tip of each Gahagan biface. The second and third splits (LM2 and LM3) occur at points of highest curvature, and LM2 is always split on the right side of the biface when oriented in 3D space following 410 the alignment output of auto3dgm illustrated in Figure 6a. To place the final landmark (LM4), a linear measurement was used to project a reference point equidistant between LM2 and LM3. The location of that point was leveraged in placing the reference plane used to cut the spline at the location of LM4. 
Spline split at location of LM1

The horizontal tangent is calculated by drawing a horizontal line above the tip of the biface using the tangent as a common constraint, and the horizontal as the independent constraint. To split the $3 \mathrm{D}$ spline at the location of the horizontal tangent, a reference point was inserted at the location of the tangent in the 2D sketch (Figure 8, a), followed by a reference plane (Figure 8 in white, $\mathrm{a}$ and $\mathrm{b}$ ) using the pick point and normal axis function where the reference point (h-tangent) was used as the pick point, and the right plane as the normal axis (Figure 8, a). The 3D spline was then cut at the location where the reference plane intersected with the spline (Figure 8 , a).

Spline split at locations of LM2 and LM3

The point of highest curvature on either side of the basal edge was calculated using the curvature function in the Accuracy Analyser (Figure 8, c and d). This function displays the curvature flow as a continuous colour plot across the area of the curve. In this instance, curvature is defined as the amount by which a geometric shape deviates from being flat or straight in the case of a line. The curvature is displayed in different colours according to the local radius, and is calculated in only one direction ( $\mathrm{U}$ or $\mathrm{V}$ ) along the curve. Using this tool, the two points of highest curvature were located between the basal and lateral edges on either side of each biface where the local radius measure was largest (Figure 8, c and d). The alignment and orientation of each biface was dictated 435 by the auto3dgm output, and the landmarking protocol follows the output mesh orientation, where LM2 was always placed on the right side of the basal edge, and LM3 on the left.

Spline split at location of $\mathrm{LM}_{4}$

One additional landmark (LM4) was placed at the centre of the base. The location of this landmark was identified by calculating the linear distance between LM2 and LM3, and projecting a reference point equidistant between the two. A reference plane was added using the ctrl-div as the pick point, and the 


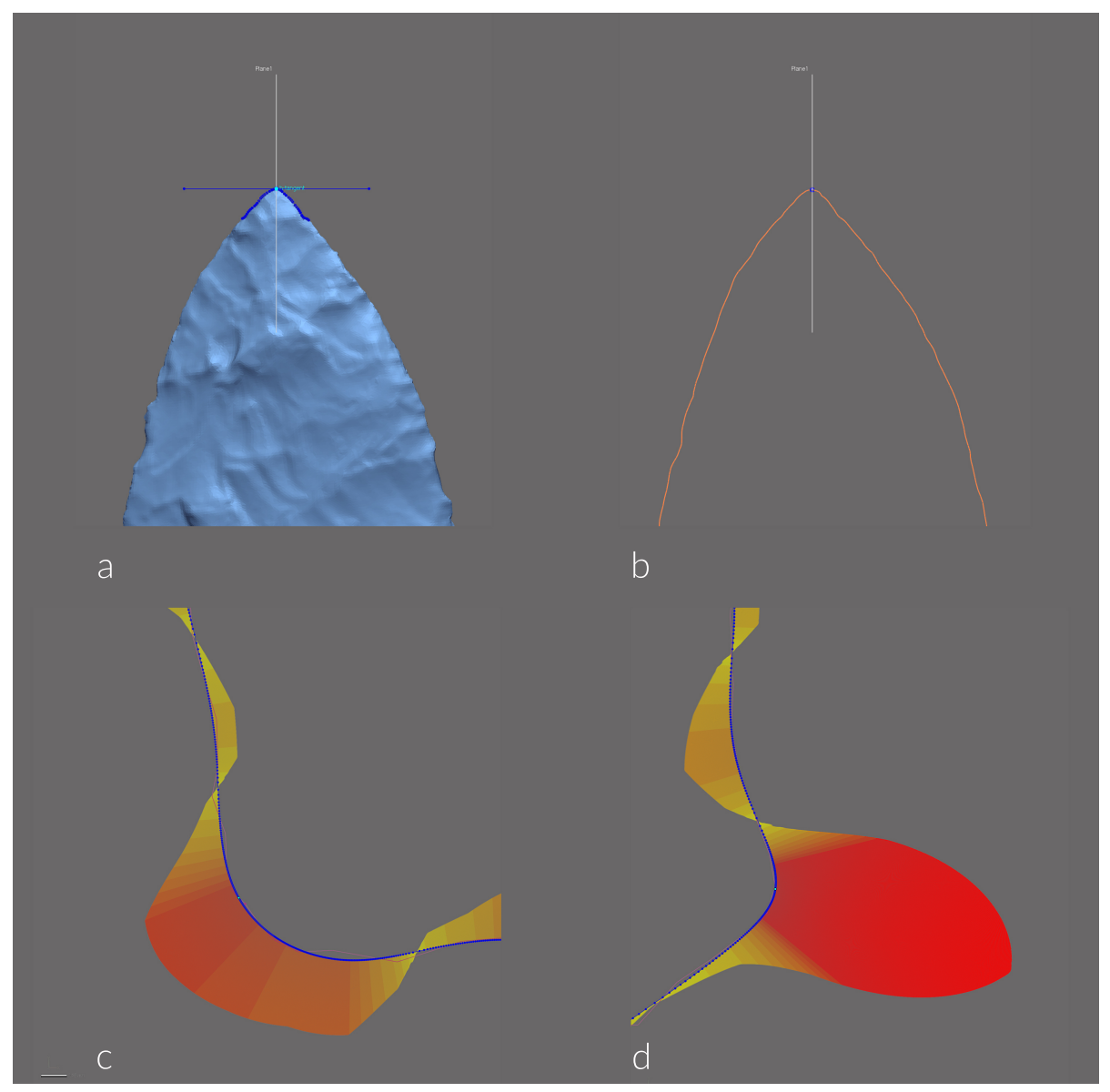

Figure 8: Horizontal tangent calculated, followed by insertion of reference point and reference plane (a). Reference plane used to cut spline at location of the horizontal tangent (b). Points of highest curvature calculated (light blue) at left (c) and right (d) intersection of lateral and basal edges. Additional information related to the landmarking protocol used in this study can be found in the supplementary material at https://github.com/akselblaise/gahaganmorph2/blob/master/analysis/landmarking-protocol.md (Selden Jr., 2020).

right plane as the normal axis. The spline was then split at the intersection of the reference plane and the basal spline (Selden Jr., 2020).

\section{Final configuration}

Through the preceding protocol, the initial spline was split into four discrete splines. These splines articulate with components of bifacial morphology that 
can be compartmentalised in the subsequent analyses (i.e., blade/base morphological integration, etc.) (Selden Jr., 2020). This rigourous landmarking proto450 col provides the requisite foundation needed to carry out replicable analyses of Gahagan biface morphology in three dimensions, further increasing the precision of the geometric morphometric analysis (Selden Jr., 2020). Landmarks 1-4 were placed at the location of each spline split (blue points, below). Equidistant semilandmarks were then added to each of the four splines; 20 between LM1 and

455 LM2, five between LM2 and LM4, five between LM4 and LM3, and 20 between LM3 and LM1 (Selden Jr., 2020).

Superficially, this constellation of landmarks and semilandmarks appears similar to the 2D configuration used in the previous study (Selden Jr. et al., 2018). However, this landmarking protocol captures the morphological variation

${ }_{460}$ that articulates with axial twisting introduced by knappers through the practise of bifacial beveling (Figure 9) (Selden Jr., 2020). Thus, this constellation of landmarks and semilandmarks provides for greater precision in the geometric morphometric analysis, marking a substantive advancement in those analytical protocols used to achieve a more complete and holistic analysis of Gahagan 465 biface morphology (Selden Jr., 2020).

\section{Analysis}

Landmark data were aligned to a global coordinate system (Kendall, 1981, 1984; Slice, 2001), achieved through generalised Procrustes superimposition (Rohlf and Slice, 1990) performed in R 3.6.1 (R Core Development Team,, 2020) 470 using the geomorph library v.3.1.2 (Adams et al., 2017; Adams and OtárolaCastillo, 2013). Procrustes superimposition translates, scales, and rotates the coordinate data to allow for comparisons among objects (Gower, 1975; Rohlf and Slice, 1990). The geomorph package uses a partial Procrustes superimposition that projects the aligned specimens into tangent space subsequent to 475 alignment in preparation for the use of multivariate methods that assume linear space (Rohlf, 1999; Slice, 2001).

Principal components analysis (Jolliffe, 2002) was used to visualise shape 


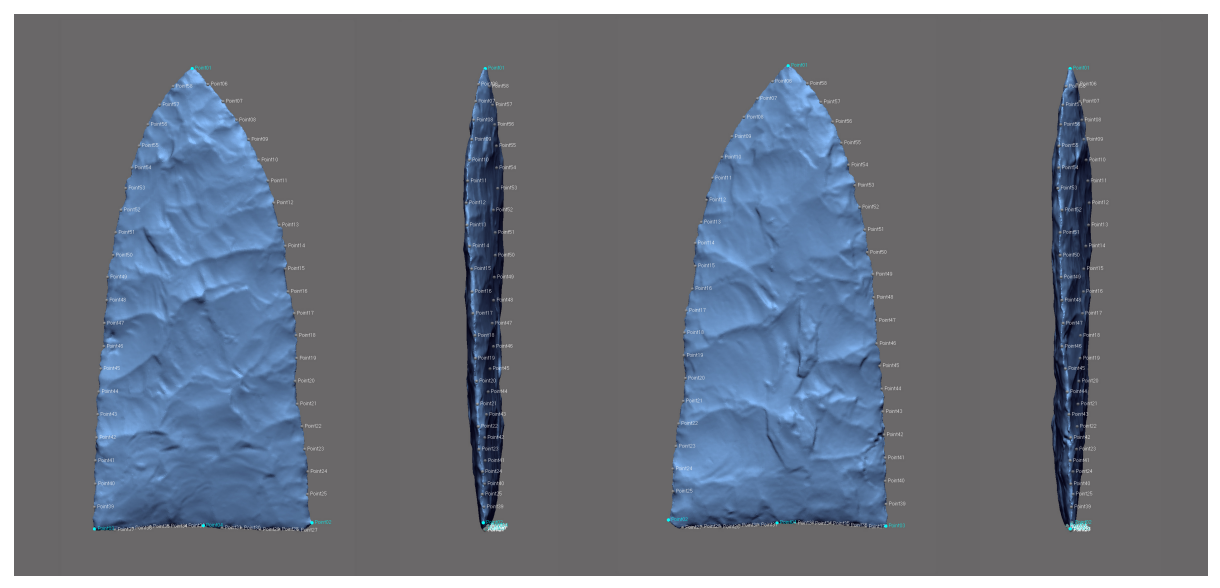

Figure 9: Landmark (blue) and semilandmark (white) placement. Note the axial twisting associated with beveling when the biface is aligned to the plane that intersects the first three landmarks. Additional information related to the landmarking protocol used in this study can be found in the supplementary material at https://github.com/akselblaise/gahaganmorph2/blob/master/analysis/landmarking-protocol.md (Selden Jr., 2020).

variation among the bifaces. The shape changes described by each principal axis are commonly visualised using thin-plate spline warping of a reference 3D mesh (Klingenberg, 2013; Sherratt et al., 2014). A residual randomisation permutation procedure (RRPP; $\mathrm{n}=10,000$ permutations) was used for all Procrustes ANOVAs (Adams and Collyer, 2015; Collyer and Adams, 2018), which has higher statistical power and a greater ability to identify patterns in the data should they be present (Anderson and Ter Braak, 2003). To as485 sess whether shape changes with size (allometry), and differs by group (region), Procrustes ANOVAs (Goodall, 1991) were also run that enlist effect-sizes (zscores) computed as standard deviates of the generated sampling distributions (Collyer et al., 2015). Procrustes variance was used to discriminate between regions and compare the amount of shape variation (morphological disparity)

490 (Zelditch et al., 2004), estimated as the Procrustes variance using residuals of linear model fit (Adams et al., 2017). 


\section{Results}

The mean consensus configuration and Procrustes residuals were calculated using a generalised Procrustes analysis (GPA) (Mitteroecker and Gunz, 2009,

495 Figure 3) (Figure 10). This initial view of the dataset can be used to illustrate the morphological variation that occurs in each region and throughout the combined sample. As an exploratory measure, GM methods - to include GPA - aid in clarifying shape differences associated with each population and in the production of novel a posteriori hypotheses (Mitteroecker and Gunz, 2009). The mean consensus configuration for the sample from each region points toward a potentially significant difference in Gahagan biface morphology between the southern Caddo area and central Texas. Further information and detail related to the analytical outputs used in this study can be found in the supplementary materials (Selden Jr., 2020).

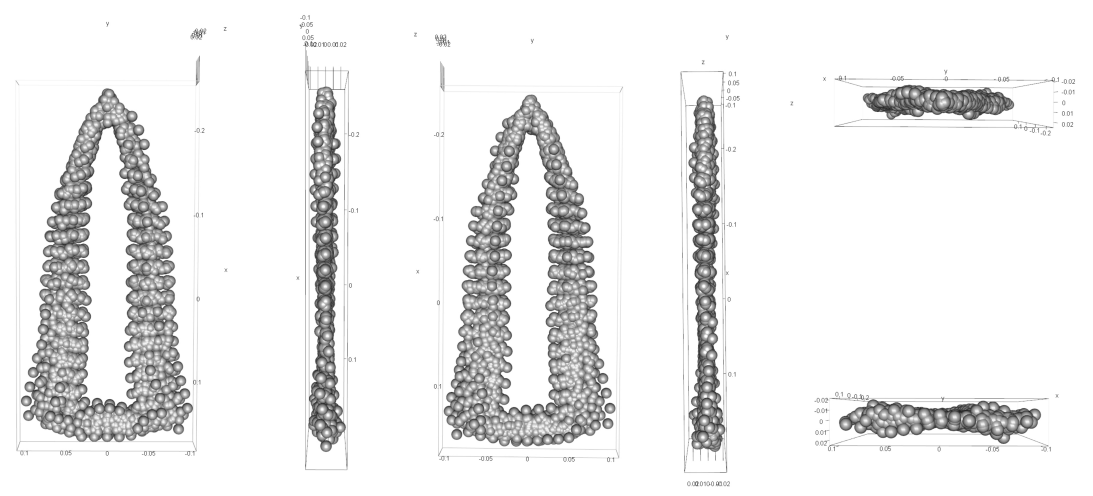

Figure 10: Results of generalised Procrustes analysis. Additional information related to the GPA, including the code needed to reproduce these results, can be found in the supplemental materials at https://github.com/aksel-blaise/gahaganmorph2/blob/master/analysis/baseanalysis.md (Selden Jr., 2020).

Principal components analysis (PCA) was conducted on scaled, translated, and rotated landmarks, and demonstrates that the first two PCs account for 62.46 (PC1) and 14.48 (PC2) percent of the variation in Gahagan biface shape 
(Figure 11) (Selden Jr., 2020). Together, PC1 and PC2 account for over 77 percent of shape variation for Gahagan bifaces, with each remaining PC representing less than six percent of the variation (Selden Jr., 2020). The first two PCs are plotted in Figure 11, where the consensus configuration (gray) and landmarks (black) represent the shape changes along PC1 and PC2. This plot indicates that shape changes associated with PC1 articulate with blades that range from broad at the minimum to narrow at the maximum, and base shapes that range from flat to slightly concave. Shape changes associated with PC2 are dominated by differences in shapes that range from a narrow blade with a broad convex base at the minimum to a broad blade with a narrow concave base at the maximum.

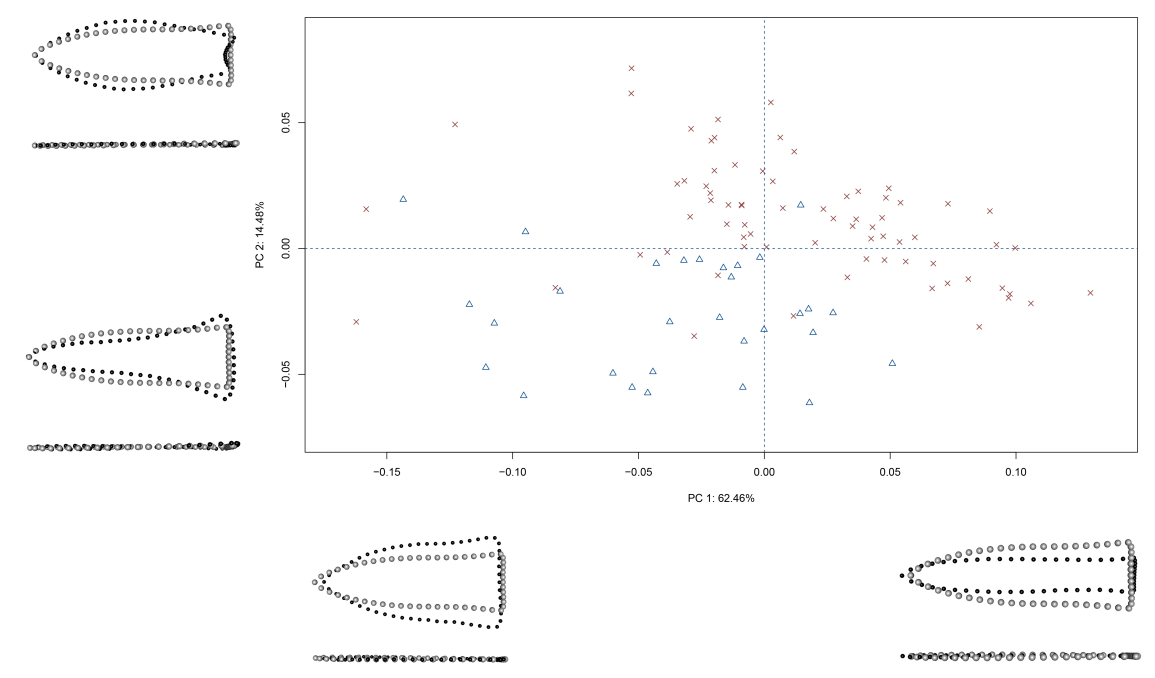

Figure 11: Principal components analysis plot (PC1/PC2) for Gahagan bifaces by region, where blue triangles represent bifaces from central Texas, and red X's represent those from the southern Caddo area. Reference shapes include the consensus configuration in gray, and the extremes of PC1 and PC2 in black. Additional information related to the PCA, including the full listing of results and the code needed to reproduce the results, can be found in the supplemental materials at https://github.com/aksel-blaise/gahaganmorph2/blob/master/analysis/baseanalysis.md (Selden Jr., 2020). 
A Procrustes ANOVA was then used to test whether a significant difference difference in allometry $(\mathrm{RRPP}=10,000 ; \mathrm{Rsq}=0.07453 ; \operatorname{Pr}(>\mathrm{F})=6 \mathrm{e}-04)$ (Figures 12 and 13) (Selden Jr., 2020). A second Procrustes ANOVA was used to test whether a significant difference exists in biface shape by region (southern Caddo area compared with central Texas), and results do indicate a significant difference in biface shape by region $(\mathrm{RRPP}=10,000 ; \mathrm{Rsq}=0.13905 ; \operatorname{Pr}(>\mathrm{F})=$ 1e-04) (Selden Jr., 2020). A comparison of mean consensus configurations was used to characterise intraspecific shape variation of Gahagan bifaces from the southern Caddo area and central Texas (Figure 12).
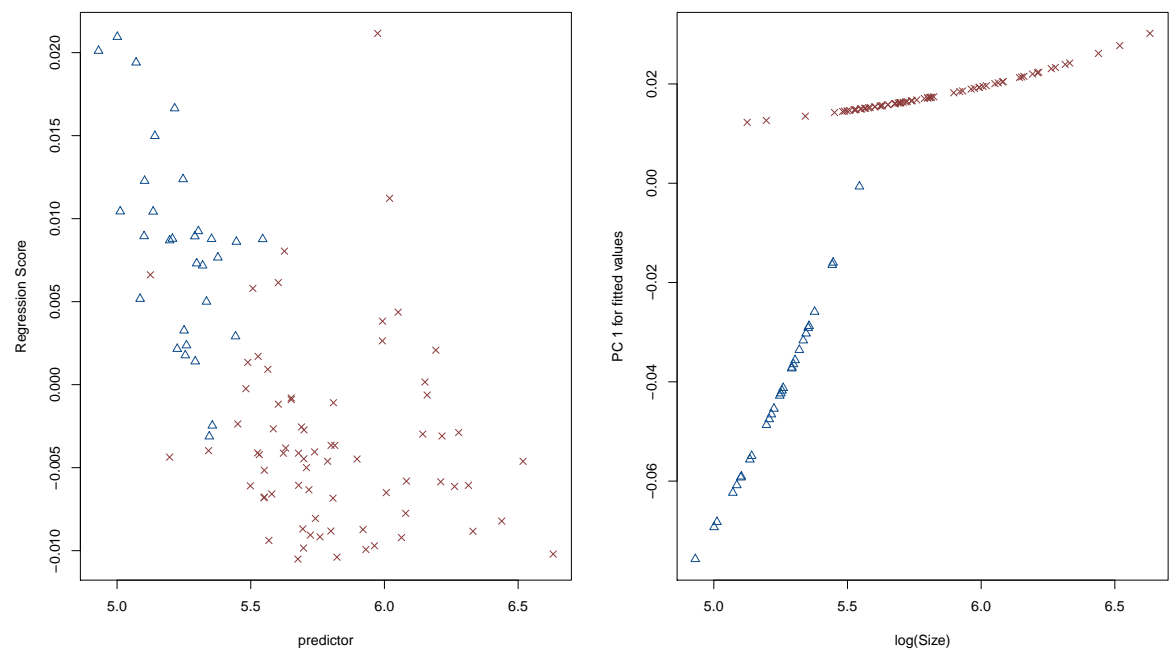

Figure 12: Measures of Gahagan biface morphology as a function of size for bifaces from both regions. Regression scores of biface shape versus $\log$ (CentroidSize) (left), and predicted values of biface shape from region-specific regressions versus $\log$ (Size) (right). Additional information related to the analysis of Gahagan biface form, including the code needed to reproduce these results, can be found in the supplemental materials at https://github.com/akselblaise/gahaganmorph2/blob/master/analysis/base-analysis.md (Selden Jr., 2020).

Those results characterised in Figures 12 and 13 illustrate differences in Gahagan biface form (shape + size), and further inquiry into potential allometric 


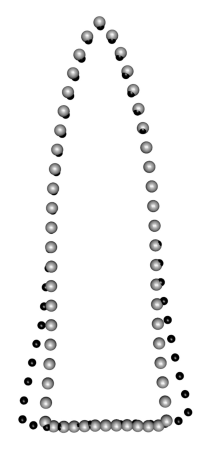

minimum

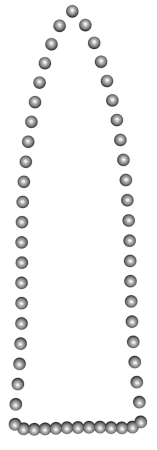

maximum

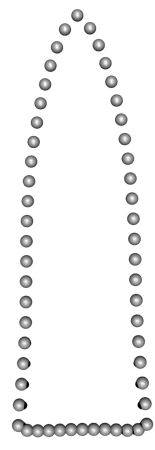

minimum

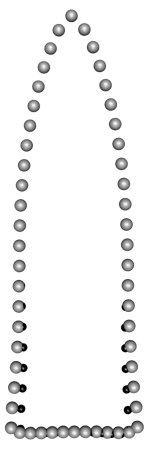

maximum

Figure 13: Measures of Gahagan biface morphology as a function of size for bifaces from both regions, where small and large specimens from each region (black spheres) are contrasted with the consensus configuration (gray spheres).

trends associated with Gahagan bifaces will be warranted in subsequent studies. In biology and biological anthropology, where these tools were developed, Figure 12 (right) would be read from left-to-right as the size of the biological specimen increases. However, lithic production and use is representative of 535 a reductive process, meaning that this figure must be read from right to left, where instead of reflecting a potential morphological convergence in the form of biological specimens, it illustrates a potential morphological divergence in the form of Gahagan bifaces. This result could be bolstered by a study of Gahagan biface retouch. Through characterising retouch, hypotheses regarding the morphological trajectories associated with resharpening can be developed and tested.

Similarly, by reading Figure 13 from left to right, or right to left, it may be tempting to infer a morphological continuum. However, these two populations of Gahagan bifaces differ significantly in shape and size (Figure 14), as demonstrated by the results of the ANOVAs (Selden Jr., 2020). The primary driver of 
those shape differences that discriminate between Gahagan bifaces from central Texas and the southern Caddo area is basal morphology (Figures 13 and 14).

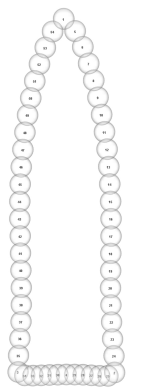

Southern Caddo Area

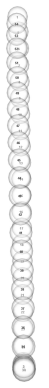

Central Texas
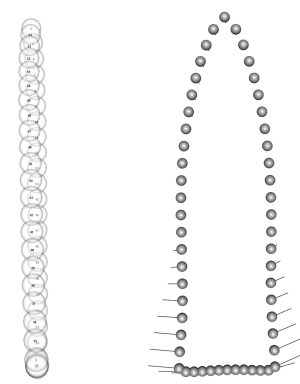

Compare Mean Shapes

Figure 14: Mean shapes for Gahagan bifaces from the southern Caddo area (left) and central Texas region (centre). In the comparison of the two (right), the southern Caddo area is represented by gray spheres, and the central Texas region by linear vectors.

The test of morphological disparity by shape yielded a result that is not significant (Selden Jr., 2020). This indicates that the Gahagan bifaces from the similar, allowing for the interpretation that neither population was participating in a practise (whether production or retouch) that led to a more morphologicallyrestricted method of biface manufacture (i.e., specialisation). However, the test of morphological disparity by size yielded a significant result (Selden Jr., 2020). area exhibit a greater diversity in size than the central Texas sample.

\section{Discussion}

This comparison of the largest assemblages of Gahagan bifaces recovered from the southern Caddo area and central Texas highlighted differences in the 
(Figures 10 - 14) associated with previously classified specimens (Selden Jr., 2020). The shift from a 2D to a $3 \mathrm{D}$ analysis allowed for the inclusion of those morphological attributes (axial twisting) associated with the practise of beveling (Figure 15), which was found to be more pronounced in the central Texas sample (Selden Jr., 2020). Differences in form (shape + size) also indicate potentially divergent Gahagan biface morphologies between the two regions, a characteristic that is most pronounced in the smallest specimens (Figure 12) (Selden Jr., 2020). Given the significant differences exhibited in the morphology of Gahagan bifaces from the two regions, paired with noteworthy differences in temporal and spatial attributes, it is concluded that these bifaces represent different tools used for different purposes in different culture areas.
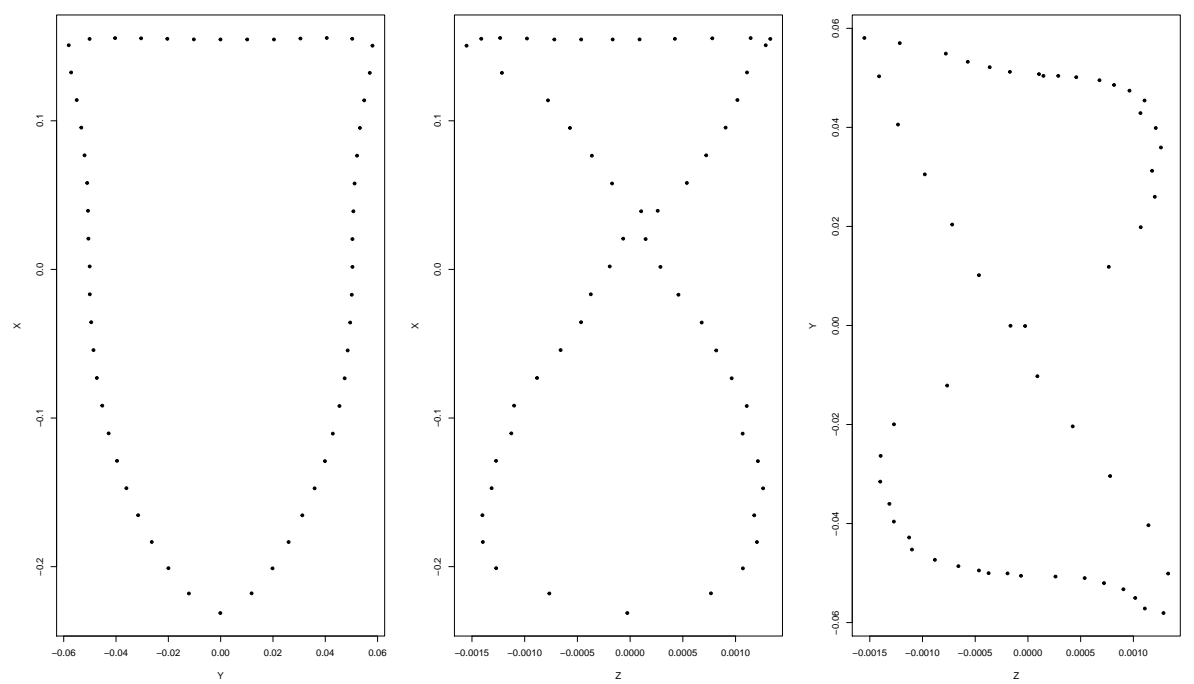

Figure 15: Two-dimensional plot of consensus configuration illustrating morphological characteristics associated with axial twisting (middle and right), which were absent from the previous 2D analysis. Additional information related to this figure, including the code needed to reproduce these results, can be found in the supplemental materials at https://github.com/akselblaise/gahaganmorph2/blob/master/analysis/base-analysis.md (Selden Jr., 2020).

Further work will be necessary to bolster the central Texas sample to include additional Gahagan bifaces from that region. The difference noted be- 
tween the central Texas and southern Caddo area samples may align with morphological differences that occur between Gahagan and Friday bifaces (Turner and Hester, 1999, 254-255). Friday bifaces were described by Jelks (1962), are distributed across central Texas, and include a temporal range from the Late Archaic through the Late Prehistoric (Turner and Hester, 1999, 254).

\section{A theoretical discrepancy related to Gahagan biface size}

Biface size was found to differ significantly between the southern Caddo area and the central Texas region (Selden Jr., 2020). This was demonstrated in the results of this geometric morphometric study, which can also be visualised in a simple comparison of centroid size by region (Selden Jr., 2020). The bulk of the southern Caddo area sample comes from burial contexts, and little work has been carried out to characterise the raw material used in Gahagan biface production. While one group of investigators discerned that Gahagan bifaces had been manufactured using Woodford, Battiest, and Ogallala cherts, as well as cherts from the Kiamichi Mountains (Banks and Winters, 1975), it is generally believed that the bulk of Gahagan bifaces from the southern Caddo area were crafted using Edwards chert from central Texas. Thus, those bifaces found closest to the source of raw material (central Texas) are smaller than those found at a greater distance from the raw material source (southern Caddo area).

That the size of Gahagan bifaces recovered nearest the (presumed) raw material source in central Texas is generally smaller than those found in the southern 595 Caddo area is an observation that has not been previously noted. Further work is warranted to assess retouch on this sample of Gahagan bifaces. Should it be determined that the central Texas sample is more heavily retouched than the sample from the southern Caddo area, then - when combined with the differences in spatial, temporal, and morphological attributes characterised in this study - those Gahagan bifaces found in central Texas may have enjoyed an appreciably different cultural function than those found in the southern Caddo area.

Shafer (2006) has posited that the presence of Gahagan bifaces in cen- 
tral Texas, when found in tandem with additional diagnostic artefacts (i.e., Caddo ceramics, metapoidal beaming tools, bone needles, or Bonham-Alba arrow points) represents a possible connection to the occupants of the George C. Davis site. While that may indeed be possible, this study demonstrates a fundamental difference in the size, shape, and form of Gahagan bifaces from central Texas, indicative of a previously unrecognised variant of Gahagan bifaces, or what may be a different type of biface altogether.

\section{Future directions}

There are substantive challenges associated with the interpretation of Gahagan biface morphology. Shafer (1973) notes that the makers of Gahagan bifaces likely resided at or near a location with ample raw materials. The working theory that Gahagan bifaces were not a product of Caddo manufacture is further evidenced by the absence of production failures at Caddo sites, and the absence of similar, locally-sourced raw materials. In a comparison of lithic reduction strategies, Shafer (1974) compared the debitage sample from the western excavations at the George C. Davis site with that of 41MQ4, an Archaic (preceramic) site located around $100 \mathrm{~km}$ south of the Davis site, where raw material quality likely posed similar limitations on makers. Results indicated that the reduction strategy employed by the Caddo at George C. Davis was distinct from that of the Archaic sample (Shafer, 1974). That the Caddo are thought to have employed a distinct lithic reduction strategy is key to the interpretation of Caddo ${ }_{625}$ stone tools, which may be further evidenced through retouch or refurbishment efforts. However, discriminating between patterns of Gahagan biface flake scars and debitage manufactured by central Texas knappers (Quigg et al., 2014) and those made later by the Caddo is a substantive challenge that has not been addressed.

While true that many biface types may not warrant the time and labour investment associated with 3D data collection and analysis, 3D is necessary for the study of Gahagan bifaces. Morphological attributes associated with axial twisting and beveling hold substantive analytical value beyond the current 
study, and those data will be employed in a variety of ballistic simulations akin to the efforts of Lipo et al. (2012). Due to the amount of axial twisting and beveling across the sample, other geometric morphometric approaches-like those aimed at discriminating among flaking patterns using EFA (Sholts et al., 2012; Gingerich et al., 2014; Sholts et al., 2017) - do not work for Gahagan bifaces. As a means of expanding upon these efforts, the next iteration of the analysis will include landmarks that articulate with a series of longitudinal crosssections placed between the semilandmarks along the lateral edges (Figure 16, left).

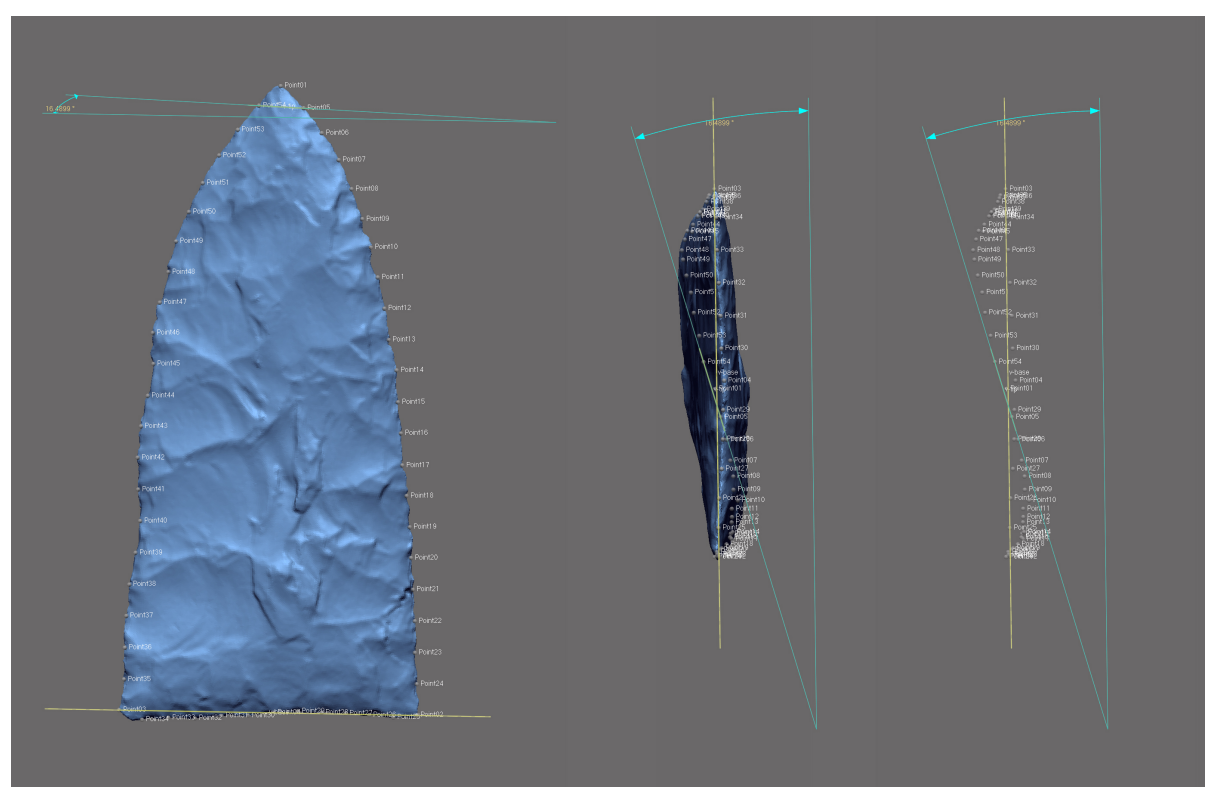

Figure 16: Degree of axial twisting calculated between two vectors placed between landmarks 2 and 3 , and semilandmarks 5 and 54 .

Although not a component of the current analysis, attributes associated with retouch are expected to articulate with beveling. Previously published methods of codifying and analysing retouch (Andrefsky, 2006; Smallwood, 2010) are being integrated into this analytical programme, and another measure is under active development. Further work is needed to refine the latter approach; however, the measure is introduced here as it may hold value for studies that are currently 
planned or underway.

Enlisting the reference geometry used in the development of the current landmark configuration, the measure is comprised of an angle that occurs between two linear vectors. To calculate the angle from the aligned mesh, one vector is placed between landmarks 2 and 3 (base), then another between semilandmarks 5 and 54 (immediately below the tip) (Figure 16, right), after which the angle between the two vectors can be calculated. It is not known whether this measure will correlate with those associated with retouch. However, should this angle be found to correlate with attributes related to retouch, size, spin torque, or other useful measures, it could hold value in future analyses.

\section{Conclusion}

Through the enlistment of the largest samples of Gahagan bifaces found across two geographic regions, this 3D geometric morphometric study highlights those significant morphological differences that occur between Gahagan bifaces recovered from central Texas and the southern Caddo area. The shift to a 3D analysis also allowed for the added observation that axial twisting is more appreciable in the central Texas sample than in the sample from the southern Caddo area. Whether these differences in shape, form, and size are representative of different uses, or an altogether different biface type (or unrecognised Gahagan variant) remains unknown. Further work will be necessary to incorporate Gahagan bifaces from additional sites to begin parsing the more nuanced variation in

670 Gahagan biface morphology. Studies of raw material and retouch would further increase the resolution of these results, perhaps aiding in clarifying the possible functions of these different biface shapes.

\section{Data Accessibility Statement}

Data and code associated with this analysis can be accessed through the

GitHub repository, which is digitally curated on the Open Science Framework (OSF). That repository holds the specifics for the date calibrations and Bayesian 
model, details associated with modeling missing geometry, a detailed overview of the 3D landmarking protocol, and the specifics related to the 3D geometric morphometric analysis. All 3D scan data (unprocessed and processed) are embargoed for a period of five years from the date of the last manuscript submission that employs them. The unprocessed 3D scan data were uploaded to the OSF, where the preprint of this paper and all supplementary materials are made available (Selden Jr., 2020).

\section{Acknowledgments}

We extend our gratitude to the Caddo Tribe of Oklahoma, the Williamson Museum at Northwestern State University, the Louisiana State Exhibit Museum, the Texas Archeological Research Laboratory at The University of Texas at Austin, the Brazos Valley Museum of Natural History, the Texas Parks and Wildlife Department, and the Sam Noble Oklahoma Museum of Natural Science for the requisite permissions and access needed to generate the scans of Gahagan bifaces. Thanks to Harry J. Shafer, Jeffrey S. Girard, Hiram F. (Pete) Gregory, Julian A. Sitters, Timothy K. Perttula, and David K. Thulman for their comments on a draft of this manuscript. Thanks also to Dean C. Adams, Michael L. Collyer, Emma Sherratt, Lauren Butaric, and Kersten Bergstrom for their constructive criticisms, comments, and suggestions throughout the development of this research programme, and to the editors and anonymous reviewers for their comments and constructive criticisms, which further improved the manuscript.

Components of this analytical work flow were developed and funded by a Preservation Technology and Training grant (P14AP00138) to RZS from the National Center for Preservation Technology and Training, and funding to scan the Gahagan bifaces at the Williamson Museum at Northwestern State University, Louisiana State Exhibit Museum, Texas Archeological Research Laboratory at The University of Texas at Austin, and Sam Noble Oklahoma Museum of Natural Science was provided to RZS by the Heritage Research Center at 705 Stephen F. Austin State University. 


\section{References}

Adams, D. C. and M. L. Collyer (2015). Permutation Tests for Phylogenetic Comparative Analyses of High-Dimensional Shape Data: What you Shuffle Matters. Evolution 69(3), 823-9.

Adams, D. C., M. L. Collyer, A. Kaliontzopoulou, and E. Sherratt (2017). Package 'geomorph': Geometric Morphometric Analyses of 2D/3D Landmark Data. $\mathrm{R}$ package version 3.0.5.

Adams, D. C. and E. Otárola-Castillo (2013). geomorph: An R Package for the Collection and Analysis of Geometric Morphometric Shape Data. Methods in Ecology and Evolution 4(4), 393-399.

Anderson, M. J. and C. J. F. Ter Braak (2003). Permutation Tests for MultiFactoral Analysis of Variance. Journal of Statistical Computation and Simulation 73(2), 85-113.

Andrefsky, W. (2006). Experimental and Archaeological Verification of an Index of Retouch for Hafted Bifaces. American Antiquity 71(04), 743-757.

Archer, W. and D. R. Braun (2010). Variability in Bifacial Technology at Elandsfontein, Western Cape, South Africa: A Geometric Morphometric Approach. Journal of Archaeological Science 37(1), 201-209.

Archer, W., P. Gunz, K. L. van Niekerk, C. S. Henshilwood, and S. P. McPherron 725 (2015). Diachronic Change within the Still Bay at Blombos Cave, South Africa. PLoS One 10(7), e0132428.

Archer, W., C. M. Pop, P. Gunz, and S. P. McPherron (2016). What is Still Bay? Human Biogeography and Bifacial Point Variability. Journal of Human Evolution 97, 58-72.

730 Archer, W., C. M. Pop, Z. Rezek, S. Schlager, S. C. Lin, M. Weiss, T. Dogandžić, D. Desta, and S. P. McPherron (2017). A Geometric Morphometric 
Relationship Predicts Stone Flake Shape and Size Variability. Archaeological and Anthropological Sciences.

Banks, L. D. and J. Winters (1975). The Bentsen-Clark Site, Red River County, Archeological Society.

Barceló, J. A. (2010). Visual Analysis in Archaeology. An Artificial Intelligence Approach. In A. M. T. Elewa (Ed.), Morphometrics for Nonmorphometricians, Lecture Notes in Earth Science, pp. 93-156. New York: Springer.

Birkhoff, G. D. (1933). Aesthetic Measure. Cambridge: Harvard University Press.

Bond, C. (1978). Three archeological sites at hoxie bridge, williamson county, texas. Report, Anthropology Laboratory, Texas A\&M University, Report No. 43.

Boyer, D. M., J. Puente, J. T. Gladman, C. Glynn, S. Mukherjee, G. S. Yapuncich, and I. Daubechies (2015). A new fully automated approach for aligning and comparing shapes. Anat Rec (Hoboken) 298(1), 249-76.

Buchanan, B. and M. Collard (2010). A Geometric Morphometrics-Based Assessment of Blade Shape Differences among Paleoindian Projectile Point Types from Western North America. Journal of Archaeological Science 37(2), $350-359$.

Buchanan, B., M. Collard, M. J. Hamilton, and M. J. O'Brien (2011). Points and Prey: A Quantitative Test of the Hypothesis that Prey Size Influences early Paleoindian Projectile Point Form. Journal of Archaeological Science 38(4), $852-864$.

Bush, V. (1945). Science, the Endless Frontier: A Report to the President on a Program for Postwar Scientific Research. Technical report, United States Government Printing Office. 
Caruana, M. V., S. Carvalho, D. R. Braun, D. Presnyakova, M. Haslam, W. Archer, R. Bobe, and J. W. K. Harris (2014). Quantifying Traces of Tool Use: A Novel Morphometric Analysis of Damage Patterns on Percussive Tools. PLoS One 9(11), e113856.

Chitwood, D. H. (2014). Imitation, Genetic Lineages, and Time Influenced the Morphological Evolution of the Violin. PLoS One 9(10), e109229.

Collyer, M. L. and D. C. Adams (2018). RRPP: An R Package for Fitting Linear Models to High-Dimensional Data using Residual Randomization. Methods in Ecology and Evolution 9(7), 1772-1779.

Collyer, M. L., D. J. Sekora, and D. C. Adams (2015). A Method for Analysis of Phenotypic Change for Phenotypes Described by High-Dimensional Data. Heredity 115(4), 357-65.

Corti, M. (1993). Geometric Morphometrics: An Extension of the Revolution. Trends in Ecology 83 Evolution 8(8), 302-303.

Emerson, T. E. and J. S. Girard (2004). Dating Gahagan and its Implications for Understanding Cahokia-Caddo Interactions. Southeastern Archaeology 23(1), $57-64$.

Fox, A. N. (2015). A Study of Late Woodland Projectile Point Typology in New York using Elliptical Fourier Outline Analysis. Journal of Archaeological Science: Reports 4, 501-509.

Gadus, E., R. Fields, and K. Kibler (2006). Data Recovery Excavations at the J. B. White Site (41MM341), Milam County, Texas. Index of Texas Archaeology: Open Access Gray Literature from the Lone Star State 2006(1), Report 10.

Gero, J. and J. Mazzullo (1984). Analysis of Artifact Shape Using Fourier Series in Closed Form. Journal of Field Archaeology 11(3), 315.

Gingerich, J. A. M., S. B. Sholts, S. K. T. S. Wärmländer, and D. Stanford (2014). Fluted Point Manufacture in Eastern North America: An Assessment 
of Form and Technology using Traditional Metrics and 3D Digital Morphometrics. World Archaeology 46(1), 101-122.

Girrulat, I. C. (2006). Contribution of Geometric Morphometrics to the Study of Archaeological Ceramics. Revista Werken 8, 57-75.

Goodall, C. (1991). Procrustes Methods in the Statistical Analysis of Shape. Journal of the Royal Statistical Society. Series B (Methodological) 53(2), 285339.

Gower, J. C. (1975). Generalized Procrustes Analysis. Psychometrika 40(1), $33-51$.

Hixson, C. and B. Whitley (2020). A pre-toyah component at the baker site, san saba county, texas. Bulletin of the Texas Archeological society 91, (in press).

Jelks, E. B. (1962). The Kyle Site: A Stratified Central Texas Aspect Site in Hill Country, Texas. The University of Texas, Department of Anthropology, Archaeology Series, No. 5. Austin, Texas.

Jolliffe, I. T. (2002). Principal Component Analysis. New York: Springer.

Kendall, D. (1981). The Statistics of Shape, pp. 75-80. New York: Wiley.

Kendall, D. G. (1984). Shape Manifolds, Procrustean Metrics, and Complex Projective Spaces. Bulletin of the London Mathematical Society 16(2), 81121.

Klingenberg, C. P. (2013). Visualizations in Geometric Morphometrics: How to Read and How to Make Graphs Showing Shape Changes. Hystrix 24(1), $15-24$.

Lenardi, M. J. and D. E. Merwin (2010). Towards Automating Artifact Analysis: A Study Showing Potential Applications of Computer Vision and Morphometrics to Artifact Typology. In A. M. T. Elewa (Ed.), Morphometrics 
for Nonmorphometricians, Lecture Notes in Earth Sciences, pp. 289-306. New York: Springer.

Lipo, C. P., R. C. Dunnell, M. J. O'Brien, V. Harper, and J. Dudgeon (2012). Beveled Projectile Points and Ballistics Technology. American Antiquity $77(4), 774-788$.

Lycett, S. J. (2009). Quantifying Transitions: Morphometric Approaches to Palaeolithic Variability and Technological Change. In M. Camps and P. Chauhan (Eds.), Sourcebook of Paleolithic Transitions, pp. 79-92. Springer.

Lycett, S. J. and N. von Cramon-Taubadel (2013). A 3D Morphometric Analysis of Surface Geometry in Levallois Cores: Patterns of Stability and Variability across Regions and their Implications. Journal of Archaeological Science 40(3), 1508-1517.

Lycett, S. J., N. von Cramon-Taubadel, and M. I. Eren (2015). Levallois: Potential Implications for Learning and Cultural Transmission Capacities. Lithic Technology, 160114014914008.

Lycett, S. J., N. von Cramon-Taubadel, and J. A. J. Gowlett (2010). A Comparative 3D Geometric Morphometric Analysis of Victoria West Cores: Implications for the Origins of Levallois Technology. Journal of Archaeological Science 37(5), 1110-1117.

Miller, E. O. and E. B. Jelks (1952). Archeological Excavations at the Belton Reservoir, Coryell County, Texas. Bulletin of the Texas Archeological and Paleontological Society 23, 168-217.

Mitteroecker, P. and P. Gunz (2009). Advances in Geometric Morphometrics. Evolutionary Biology 36(2), 235-247.

Moore, C. B. (1912). Some Aboriginal Sites on Red River. Journal of the Academy of Natural Sciences of Philadelphia 14(4), 526-636. 
Newell, H. P. and A. D. Krieger (1949). The George C. Davis Site, Cherokee County, Texas. Menasha, Wisconsin: Memoir No. 5. Society for American Archaeology.

Prewitt, E. R. (1982). Archeological Investigations at the Loeve-Fox Site, Williamson County, Texas. Prewitt \& Associates, Inc., Austin, Texas.

Quigg, M., P. Matchen, R. Ricklis, S. Gray, C. Frederick, and J. Barrett (2014). Eligibility Testing at Three Prehistoric Sites at Lynch Creek, Lampasas 845 County, Texas. Index of Texas Archaeology: Open Access Gray Literature from the Lone Star State 2014(1), Report 5.

R Core Development Team, (2020). R: A Language and Environment for Statistical Computing. Vienna, Austria: R Foundation for Statistical Computing.

Ragan, K. and B. Buchanan (2018). Assessing Collector Bias: A Geometric Morphometric Analysis of a Collection of Isolated Clovis Points from the Midcontinent. Midcontinental Journal of Archaeology 43(2), 91-111.

Ramsey, C. B. (1995). Radiocarbon Calibration and Analysis of Stratigraphy: The OxCal Program. Radiocarbon 37(2), 425-430.

Ramsey, C. B. (2017). Methods for Summarizing Radiocarbon Datasets. Radiocarbon 59(06), 1809-1833.

Reimer, P. J., E. Bard, A. Bayliss, J. W. Beck, P. G. Blackwell, C. Bronk Ramsey, C. E. Buck, H. Cheng, R. L. Edwards, M. Friedrich, P. M. Grootes, T. P. Builderson, H. Haflidason, I. Hajdas, C. Hatte, T. J. Heaton, D. L. Hoffman, A. G. Hogg, K. A. Hughen, K. F. Kaiser, B. Kromer, S. W. Manning, M. Niu, R. W. Reimer, D. A. Richards, E. M. Scott, J. R. Southon, R. A. Staff, C. S. M. Turney, and J. van der Plicht (2013). IntCal13 and Marine13 Radiocarbon Age Calibration Curves 0-50,000 Years cal BP. Radiocarbon 55(4), $1869-1887$.

Rohlf, F. J. (1999). Shape Statistics: Procrustes Superimpositions and Tangent Spaces. Journal of Classification 16(2), 197-223. 
Rohlf, F. J. and D. Slice (1990). Extensions of the Procrustes Method for the Optimal Superimposition of Landmarks. Systematic Zoology 39(1), 40-59.

Ros, J., A. Evin, L. Bouby, and M.-P. Ruas (2014). Geometric Morphometric Analysis of Grain Shape and the Identification of Two-Rowed Barley (Hordeum vulgare subsp. distichum L.) in Southern France. Journal of Archaeological Science 41, 568-575.

Schlager, S. (2017). Morpho and Rvcg - Shape Analysis in R. In Statistical Shape and Deformation Analysis, pp. 217-256.

Selden Jr., R. Z. (2017). Asymmetry of Caddo Ceramics from the Washington Square Mound Site: An Exploratory Analysis. Digital Applications in Archaeology and Cultural Heritage 5, 21-28.

Selden Jr., R. Z. (2018a). A Preliminary Study of Smithport Plain Bottle Morphology in the Southern Caddo Area. Bulletin of the Texas Archeological Society 89, 63-89.

Selden Jr., R. Z. (2018b). Ceramic Morphological Organisation in the Southern Caddo Area: Quiddity of Shape for Hickory Engraved Bottles. Journal of Archaeological Science: Reports 21, 884-896.

Selden Jr., R. Z. (2019a). Ceramic Morphological Organisation in the Southern Caddo Area: The Clarence H. Webb Collections. Journal of Cultural $\mathbf{8 8 5} \quad$ Heritage $35,41-55$.

Selden Jr., R. Z. (2019b). Louisiana Limitrophe: An Iterative Morphological Exegesis of Caddo Bottle and Biface Production. SocArXiv.

Selden Jr., R. Z. (2020). Supplementary data for paper: A quantitative assessment of intraspecific morphological variation in Gahagan bifaces from the 890 southern Caddo area and central Texas. Open Science Framework.

Selden Jr., R. Z., J. E. Dockall, and H. J. Shafer (2018). Lithic Morphological Organisation: Gahagan Bifaces from the Southern Caddo Area. Digital Applications in Archaeology and Cultural Heritage 10, e00080. 
Selden Jr., R. Z., T. K. Perttula, and M. J. O'Brien (2014). Advances in Documentation, Digital Curation, Virtual Exhibition, and a Test of 3D Geometric Morphometrics: A Case Study of the Vanderpool Vessels from the Ancestral Caddo Territory. Advances in Archaeological Practice 2(2), 1-15.

Shafer, H. J. (1973). Lithic Technology at the George C. Davis Site, Cherokee County, Texas. Ph.D. Dissertation, The University of Texas at Austin.

Shafer, H. J. (1974). Lithic Reduction Strategies at the George C. Davis Site. Louisiana Archaeology 1, 66-74.

Shafer, H. J. (2006). People of the Prairie: A Possible Connection to the Davis Site Caddo. Texas Department of Transportation and Prewitt and Associates, Inc.

Shafer, H. J., D. A. Story, and J. D. Scurlock (1964). An Investigation and Appraisal of the Archeological Resources of Belton Reservoir, Bell and Coryell Counties, Texas: 1962. Texas Archeological Salvage Project, Austin, Texas.

Sherratt, E., D. J. Gower, C. P. Klingenberg, and M. Wilkinson (2014). Evolution of Cranial Shape in Caecilians (Amphibia: Gymnophiona). Evolutionary Biology 41(4), 528-545.

Sholts, S. B., J. A. M. Gingerich, S. Schlager, D. J. Stanford, and S. K. T. S. Wärmländer (2017). Tracing Social Interactions in Pleistocene North America via 3D Model Analysis of Stone Tool Asymmetry. PLoS One 12(7), e0179933.

Sholts, S. B., D. J. Stanford, L. M. Flores, and S. K. T. S. Wärmländer (2012). Flake Scar Patterns of Clovis Points Analyzed with a New Digital Morphometrics Approach: Evidence for Direct Transmission of Technological Knowledge across early North America. Journal of Archaeological Science 39(9), 3018-3026.

Shott, M. J. (2011). History Written in Stone: Evolutionary Analysis of Stone Tools in Archeology. Evolution: Education and Outreach 4(3), 435-445. 
Shott, M. J. and B. W. Trail (2010). Exploring New Approaches to Lithic Analysis: Laser Scanning and Geometric Morphometrics. Lithic Technology 35(2), $195-220$.

Slice, D. E. (2001). Landmark Coordinates Aligned by Procrustes Analysis Do Not Lie in Kendall's Shape Space. Systematic Biology 50(1), 141-149.

Smallwood, A. M. (2010). Clovis biface technology at the Topper site, South Carolina: evidence for variation and technological flexibility. Journal of Archaeological Science 37(10), 2413-2425.

Story, D. A. (1969). 1968-1969 Field Work at George C. Davis. Newsletter of the Southeast Archaeological Conference 13, 25-32.

Story, D. A. (1972). A Preliminary Report of the 1968, 1969, and 1970 Excavations at the George C. Davis Site, Cherokee County, Texas. The University of Texas at Austin.

Story, D. A. (1997). 1968-1970 Archeological Investigations at the George C. Davis Site, Cherokee County, Texas. Bulletin of the Texas Archeological Society $68,1-113$.

Story, D. A. and S. Valastro Jr. (1977). Radiocarbon Dating and the George C. Davis Site, Texas. Journal of Field Archaeology 4 (1), 63-89.

Thompson, D. W. (1917). On Growth and Form. Cambridge: Cambridge University Press.

Thulman, D. K. (2012). Discriminating Paleoindian Point Types from Florida using Landmark Geometric Morphometrics. Journal of Archaeological Science 39(5), 1599-1607.

Thulman, D. K. (2019). A Typology of Florida Fluted Points Using Landmarkbased Geometric Morphometrics. PaleoAmerica 5(2), 181-190. 
Topi, J. R., C. S. VanPool, K. D. Waller, and T. L. VanPool (2017). The Economy of Specialized Ceramic Craft Production in the Casas Grandes Region. Latin American Antiquity, 1-21.

Turner, E. S. and T. R. Hester (1999). A Field Guide to Stone Artifacts of

Wang, W., S. J. Lycett, N. von Cramon-Taubadel, J. J. H. Jin, and C. J. Bae (2012). Comparison of Handaxes from Bose Basin (China) and the Western Acheulean Indicates Convergence of Form, not Cognitive Differences. PLoS One 7(4), e35804.

Webb, C. H. and M. Dodd Jr. (1939). Further Excavations of the Gahagan Mound: Connections with a Florida Culture. Bulletin of the Texas Archeological and Paleontological Society 11, 92-126.

Webb, C. H. and R. R. McKinney (1975). Mounds Plantation (16CD12), Caddo Parish, Louisiana. Louisiana Archaeology 2, 39-128.

Webb, W. S. and D. L. DeJarnette (1942). An Archaeological Survey of Pickwick Basin in the Adjacent Portions of the States of Alabama, Mississippi, and Tennessee. Bureau of American Ethnology.

Wilczek, J., F. Monna, P. Barral, L. Burlet, C. Chateau, and N. Navarro (2014). Morphometrics of Second Iron Age Ceramics - Strengths, Weaknesses, and 965 Comparison with Traditional Typology. Journal of Archaeological Science 50, $39-50$.

Wilczek, J., F. Monna, M. Gabillot, N. Navarro, L. Rusch, and C. Chateau (2015). Unsupervised Model-Based Clustering for Typological Classification of Middle Bronze Age Flanged Axes. Journal of Archaeological Science: Reports 3, 381-391.

Windhager, S., F. L. Bookstein, K. Grammer, E. Oberzaucher, H. Said, D. E. Slice, T. Thorstensen, and K. Schaefer (2012). "Cars Have their own Faces": 
Cross-Cultural Ratings of Car Shapes in Biological (Stereotypical) Terms.

Evolution and Human Behavior 33(2), 109-120.

975 Zelditch, M. L., D. L. Swiderski, H. D. Sheets, and W. L. Fink (2004). Geometric Morphometrics for Biologists : A Primer. Burlington: Elsevier Science. 